\title{
Physiology and Pathophysiology of the Biliary Tract: The Gallbladder and Sphincter of Oddi-A Review
}

\author{
Jose Behar \\ Department of Medicine, Rhode Island Hospital, Warren Alpert Medical School of Brown University, \\ Providence, RI 02903, USA \\ Correspondence should be addressed to Jose Behar; jose_behar@brown.edu
}

Received 23 December 2012; Accepted 9 January 2013

Academic Editors: S. Gupte, D. Xiao, and A. V. Zholos

Copyright (C) 2013 Jose Behar. This is an open access article distributed under the Creative Commons Attribution License, which permits unrestricted use, distribution, and reproduction in any medium, provided the original work is properly cited.

\begin{abstract}
The biliary tract collects, stores, concentrates, and delivers bile secreted by the liver. Its motility is controlled by neurohormonal mechanisms with the vagus and splanchnic nerves and the hormone cholecystokinin playing key roles. These neurohormonal mechanisms integrate the motility of the gallbladder and sphincter of Oddi (SO) with the gastrointestinal tract in the fasting and digestive phases. During fasting most of the hepatic bile is diverted toward the gallbladder by the resistance of the SO. The gallbladder allows the gradual entry of bile relaxing by passive and active mechanisms. During the digestive phase the gallbladder contracts, and the SO relaxes allowing bile to be released into the duodenum for the digestion and absorption of fats. Pathological processes manifested by recurrent episodes of upper abdominal pain affect both the gallbladder and SO. The gallbladder motility and cytoprotective functions are impaired by lithogenic hepatic bile with excess cholesterol allowing the hydrophobic bile salts to induce chronic cholecystitis. Laparoscopic cholecystectomy is the standard treatment. Three types of SO dyskinesia also cause biliary pain. Their pathophysiology is not completely known. The pain of types I and II usually respond to sphincterotomy, but the pain due to type III usually does not.
\end{abstract}

\section{Introduction}

This paper reviews the anatomy and physiology of the extrahepatic biliary tract as well as the pathophysiology and clinical symptoms of the inflammatory and functional disorders of its two key structures: the gallbladder and the sphincter of Oddi. There is also a brief description of generally accepted treatments for these conditions.

The extrahepatic biliary tract is a closed system designed to collect, store, and concentrate bile secreted by the liver and that is intermittently delivered to the duodenum through the bile ducts. Bile contains bile salts, a key component involved in the digestion and absorption of fats and liposolubles vitamins, and has other constituents that participate in the enterohepatic circulation including cholesterol (Ch), the most important one from the pathological point of view.

These motor functions of the biliary tract are closely integrated with the rest of the digestive system by neurohormonal mechanisms that include the vagus and splanchnic nerves and various hormones among them cholecystokinin (CCK).
They control the biliary motor activity during fasting and digestive periods.

\section{Anatomy and Physiology}

2.1. The Gallbladder. The gallbladder is a thin-walled sac usually placed between both hepatic lobes consisting of three anatomic parts: the fundus, corpus, and infundibulum [1]. Anatomically the human gallbladder is fairly similar to most mammalian species that have been subjected to experimental studies in dogs, cats, opossums, guinea pigs, prairie dogs, and mice. In some species, like the rat, the gallbladder is absent. The gallbladder ends in the cystic duct that is a passive conduit that in humans has a diameter of about $7 \mathrm{~mm}$ with a mucosa containing spiral valves (valves of Heister). This duct drains into the common bile duct without a sphincteric structure. The common bile duct courses through the head of the pancreas ending in the sphincter of Oddi, as it penetrates the duodenal wall where it forms the ampulla of Vater. The common bile duct has few unorganized muscle fibers. Neither the cystic duct nor the common bile duct has peristaltic motility. 
The histology of the gallbladder consists of mucosa with a single layer of epithelial cells, a lamina propria, a single layer of muscle that resembles the muscularis mucosa of the gastrointestinal tract, and a serosal layer [2]. The epithelial layer absorbs water and electrolytes that concentrates the gallbladder bile containing hydrophobic bile salts. The mucosa also transports small quantities of bile salts and Ch probably by passive diffusion $[3,4]$. These epithelial cells are capable of tolerating hydrophobic bile salts, even though they are highly aggressive in other organs (stomach and esophagus) because of their cytoprotective functions in which prostaglandin E2 (PGE2) plays an important role. This prostaglandin protects the epithelial cells by secreting mucin that coats the mucosa and inactivates free radicals induced by bile salts. The single muscle layer is innervated by the vagus and splanchnic nerves that synapse with intramural neurons.

The biliary tract is functionally integrated with the digestive tract by neurohormonal mechanisms in the fasting and digestive phases [1]. The liver secretes bile continuously into the intrahepatic ducts flowing into the extrahepatic ducts. The gallbladder is filled with the aid of the sphincter of Oddi (SO) where the bile is stored and concentrated in the fasting state and emptied during all three phases of the digestive periods. In the interdigestive period about $10 \%$ of the hepatic bile can drain into the duodenum occurring during intervals between the phasic contractions of the sphincter of Oddi (diastolic periods) when the secreted bile raise the ductal pressures above the sphincter of Oddi basal pressures [5]. The remaining $90 \%$ of bile is redirected toward the cystic duct to be stored in the gallbladder. The entry of bile distends the gallbladder by passive and active mechanisms. Adrenergic and noncholinergic nonadrenergic nerves mediate the active relaxation or accommodation of the gallbladder that is gradually induced by the incoming bile.

The main neurohormonal mechanisms regulating the motility of the gallbladder are the vagus and splanchnic nerves and the hormone CCK [6-8]. The vagus nerve contains afferent and efferent fibers [9]. The efferent fibers are preganglionic neurons that synapse to intramural postganglionic cholinergic neurons present within the gallbladder wall. Stimulation of the efferent fibers of the vagus nerve contracts the gallbladder that is antagonized by the ganglionic blocker hexamethonium and atropine, the muscarinic receptor antagonist. Stimulation of the splanchnic nerves relaxes the gallbladder that is blocked by propranolol [10]. This inhibitory innervation was demonstrated in atropinetreated cat gallbladder muscle strips [11]. The strips relaxed in response to electrical field stimulation that was blocked by propranolol but was unaffected by partial antagonists of the vasoactive intestinal peptide (VIP) suggesting that the stimulus was acting on sympathetic postganglionic neurons releasing epinephrine as the neurotransmitter that act primarily on beta-adrenergic receptors. However, different results were obtained when the atropine-treated cat gallbladder was relaxed by stimulating the vagus nerve. Under these experimental conditions the relaxation was resistant to propranolol but was abolished by pretreatment with an antiserum against VIP suggesting that this peptide is the neurotransmitter responsible for it [12]. It is conceivable that the VIP antiserum is a more effective antagonist against VIP than the partial VIP antagonists that were used in muscle strips. These discrepancies between in vitro and in vivo studies cannot be fully explained at this time although it is possible that both neurotransmitters are involved in the gallbladder relaxation. Further studies are needed to reconcile these different observations that were demonstrated using different experimental conditions.

During the fasting period the gallbladder maintains a moderate tonic contraction that is superimposed with nonpropulsive and propulsive contractions $[13,14]$. These tonic and rhythmic contractions were demonstrated in dogs in vivo. The nonpropulsive contractions are probably designed to keep the bile insoluble constituents in solution preventing their precipitation, particularly precipitation of $\mathrm{Ch}$ that can lead to gallstone formation. These contractions are even observed in muscle strips from normal human gallbladders [14]. The propulsive contractions empty fractions of gallbladder bile contributing to the small percentage of bile that enters the duodenum during this interdigestive period. These contractions also occur in the fasting period during the migrating motor complex that is known to stimulate the gallbladder motility. The increased number of gallbladder contractions coincides with the phase 3 of the antral migrating motor complex and with the phase 2 of the duodenum [15]. These contractions are responsible for the additional albeit small discharge of gallbladder bile in the duodenum that takes place during this period.

In the digestive period strong gallbladder contractions and sphincter of Oddi relaxation lead to the high rates of bile discharge flowing into the common bile duct and duodenum. During this period, the gallbladder motor activity like the rest of the gastrointestinal tract is influenced by the three phases of digestive process: cephalic, antral, and duodenal [16]. The cephalic phase is initiated by stimuli that activate the central nervous system, as individuals are exposed to olfactory, visual, and the taste of food. This phase is mediated by preganglionic vagal fibers that synapse with postganglionic cholinergic neurons. It is estimated that as much as $30-40 \%$ of the gallbladder bile may be emptied during this phase. Once food reaches the stomach it triggers an antral-gallbladder reflex also mediated by vagal fibers. The gallbladder empties most of its remaining contents during the intestinal phase induced by the release of CCK from the duodenum and proximal jejunum [17]. Duodenal CCK contracts the gallbladder mostly by acting directly on cholinergic neurons [6] and like with the pancreas, and it may also activate long reflexes through the vagus nerve. Meals containing proteins and fats act on duodenal CCK containing endocrine cells that stimulate vagal sensory fibers followed by activation of pre- and postganglionic cholinergic neurons [18]. Either mechanism stimulates the final pathway of postganglionic cholinergic neurons, since atropine pretreatment blocks the gallbladder contraction induced by physiological concentrations of CCK8 [19] or by a protein-fatty meal. CCK-1 receptors are also present in the gallbladder muscle, but they only can be stimulated by pharmacological concentrations of CCK, since they are not blocked by either atropine or tetrodotoxin. 
2.2. The Sphincter of Oddi: Anatomy and Physiology. The human sphincter of Oddi is approximately $10 \mathrm{~mm}$ in length and has a well-defined and strong musculature. It is similar to the sphincter of Oddi found in predominantly carnivorous species such as dogs and cats [20,21]. It has both an intra- and extramural segments. This sphincter of Oddi is anatomically and functionally independent of the duodenum. Its myoelectrical and contractile pattern are different in character and timing from those of the duodenum. The contractions of the human sphincter of Oddi are simultaneous, although they may have slight differences in configuration that at times may appear peristaltic. The presence of simultaneous contractions is consistent with its main function of acting as a resistor to bile flow.

Furthermore it is important to emphasize that the motility of the human sphincter of Oddi is quite different from that of the opossum, guinea pig, and rabbit [22]. Anatomically these herbivorous animals that eat throughout their awake period tend to have long and mostly extraduodenal sphincters. A great deal of research has been done in the opossum sphincter of Oddi. In contrast to the short human, the opossum sphincter of Oddi is approximately $3 \mathrm{~cm}$ long with clear peristaltic contractions. It facilitates the flow of bile through this segment suggesting that it behaves more like a short duct rather than a sphincter. Also, in contrast to the human sphincter of Oddi, the effect of CCK on the sphincter of these animals further illustrates these physiological differences. CCK relaxes the human, whereas it contracts the opossum sphincter of Oddi by only acting on smooth muscle receptors, since they are not blocked by tetrodotoxin [23].

The human sphincter of Oddi has fairly steady basal pressures with superimposed forceful contractions. The normal sphincter of Oddi basal pressures range from 10 to $15 \mathrm{~mm}$ $\mathrm{Hg}$ with strong phasic contractions with amplitudes of up to $150 \mathrm{~mm} \mathrm{Hg}$ [24]. Its sphincteric function is demonstrated when an indwelling cannula is placed across this sphincter. The patent sphincter of Oddi impedes gallbladder filling [25]. The human sphincter of Oddi also prevents duodenal reflux into the common bile duct because its basal pressures are higher than duodenal basal pressures and its phasic contractions are almost simultaneous with the duodenal phasic contractions. This functional role of the human sphincter of Oddi was elegantly demonstrated by examining its motility and bile flow into the duodenum. The motility and flow from the gallbladder through the sphincter of Oddi to the duodenum were determined by a combination of cholecystocholagiography and measurements of the sphincter of Oddi pressures. These studies were performed using a combination of a hydraulic-capillary infusion system and pressure measurements that correlated flow and motility changes with the plasma concentrations of gastrointestinal hormones [26]. These studies showed that bile flow was limited when the sphincter of Oddi contractions occur at the rate of 2 to 4 per minute. However, no bile flow was observed when the rates were from 8 to 10 contractions per minute.

Exogenous or endogenous CCK causes a coordinated action contracting the gallbladder and relaxing the sphincter of Oddi and adjacent segment of the duodenum, resulting in an effective discharge of bile into the duodenum. This observation opposes the view that active sphincter of Oddi contractile activity is necessary for bile flow. Moreover reflux of air and duodenal contents into the common bile duct is observed only after the sphincter of Oddi is severed. It is therefore important to take in consideration these anatomic and functional differences when the results of experiments performed in herbivorous animals such as the opossum and guinea pig are extrapolated to explain the physiology and pathophysiology of the human sphincter of Oddi.

The sphincter of Oddi motility is regulated by neurohormonal mechanisms during the fasting and digestive periods [27]. The basal and phasic contractions are primarily generated by myogenic factors regulated by opposing actions of cholinergic and noncholinergic excitatory and nonadrenergic noncholinergic inhibitory neurons [28]. Removal of these neural actions after treatment with tetrodotoxin results in increased frequency and force of its contractions due to its predominant inhibitory innervation.

Most of the studies investigating the excitatory and inhibitory innervation have utilized pharmacological methods revealing the presence of several types of receptors. These receptors suggest potential physiological roles of neurotransmitters that regulate the motility of the sphincter of Oddi. Most of these studies were performed in the sphincter of Oddi of cats and dogs [29]. The studies performed in herbivorous animals show significant differences from the neural mechanisms that control the cat and dog sphincter of Oddi and probably from the human one [30]. There is only one human study that showed the presence of an excitatory neural pathway that included cholinergic neurons using acetylcholine as a neurotransmitter. In this study pirenzepine, a M1 selective antimuscarinic agent, decreased the amplitude of tonic and phasic contractions, whereas atropine a nonselective muscarinic antagonist only reduced the frequency of the phasic contractions [31].

Most of the pharmacological studies that were performed in cats have identified cholinergic, opiate, and serotonergic receptors that may regulate the sphincter of Oddi motor activity. The opiates receptors are predominantly excitatory mu receptors. Morphine, a mu receptor agonist, causes strong sphincter of Oddi contractions. More important it is the effect of naloxone a mu receptor antagonist. Low doses of naloxone $(40 \mathrm{mcg} / \mathrm{kg})$ blocked the effect of maximal doses of morphine and abolished both basal and phasic contractions of the sphincter of Oddi. In contrast, met-enkephalin, a delta opiate agonist, relaxes the sphincter of Oddi with a maximal relaxation induced by $8 \mathrm{mcg} / \mathrm{kg}$ [32]. The enkephalin-induced relaxation is blocked by high doses of naloxone (up to $640 \mathrm{mcg} / \mathrm{kg}$ ) or after the sphincter of Oddi is denervated with tetrodotoxin suggesting that these delta-opiate receptors are present in nonadrenergic noncholinergic inhibitory neurons.

5-hydroxytryptamine (5-HT) stimulates both excitatory and inhibitory receptors present on cholinergic and nonadrenergic noncholinergic neurons as well as on smooth muscle receptors [33]. These studies used only two 5-HT antagonists known at the time when these studies were performed. These antagonists blocked smooth muscle and nonspecific neural receptors. Additional studies are needed with more specific antagonists, since recent studies have shown that 5-HT has 
up to seven receptor subtypes. The role of these receptors and neurotransmitters in the human sphincter, however, is not known.

The potential physiological role of the above mentioned neural pathways was demonstrated by stimulating the sphincter of Oddi with motilin, a hormone known to contribute to the phase III of the migrating motor complex. These studies were carried out in cats in vivo measuring the sphincter pressures and in separate experiments the myoelectrical activity and fluid flow across the sphincter. Increasing doses of intraarterial motilin from 32 to $256 \mathrm{ng} / \mathrm{kg}$ caused higher basal pressures, force, and frequency of the phasic contractions. They also demonstrated that this sphincter functions as a resistor because lower trans sphincteric flow correlated with a concomitant increase in myoelectrical activity with a higher spike burst frequency [34]. The action of motilin was unaffected by extrinsic denervation that included cervical vagotomy or splanchnicectomy, the ganglionic blocker hexamethonium, and propranolol a beta-adrenergic antagonist. However, atropine or methysergide had a small inhibitory effect, and a combination of atropine and methysergide, naloxone alone or tetrodotoxin completely, blocked the effects of this hormone. Thus the actions of motilin further confirmed the presence of the above-mentioned intramural excitatory pathways that includes cholinergic, opiate, and serotonergic neurons. The sphincter is also regulated by an inhibitory innervation with nonadrenergic noncholinergic neurons that utilize nitric oxide and VIP as neurotransmitters [35-37]. Injection of nitric oxide donors into dog sphincter of Oddi generated nitric oxide and a concomitant relaxation.

The motility of the sphincter of Oddi, like the rest of the gastrointestinal tract, is influenced by fasting and digestive periods. During the fasting period the sphincter pressures are influenced by all four phases of the migrating motor complex [38]. The phase 3 of the migrating motor complex generates high amplitude and more frequent contractions that occur simultaneously with the duodenal component. The simultaneous occurrence of the phase 3 in both structures prevents reflux of duodenal contents (enzymes and bacteria) into the common bile duct.

During the intestinal phase of the digestive period fats and proteins release CCK from the duodenal mucosa inducing simultaneous contraction of the gallbladder and relaxation of the sphincter of Oddi and duodenum [26]. The coordinated gallbladder contraction and sphincter of Oddi and duodenal relaxation allow bile stored in the gallbladder to flow through the common bile duct and to the duodenum with minimal sphincter of Oddi and duodenal resistance. These effects of CCK are enhanced by the simultaneous actions of the vagus nerve that contracts the gallbladder and relaxes the sphincter of Oddi. They both relax the sphincter of Oddi by stimulating postganglionic nonadrenergic noncholinergic inhibitory neurons that release VIP and nitric oxide as their main neurotransmitters [12, 39]. CCK stimulates CCK-1 receptors present in nonadrenergic noncholinergic neurons, since its inhibitory effect is blocked only by tetrodotoxin and by CCK-1 receptor antagonists [28]. However, in the absence of these neurons or after treatment with tetrodotoxin CCK contracts the sphincter of Oddi by stimulating CCK-1 excitatory receptors present in its smooth muscle.

In summary, the motor functions of the biliary tract are integrated with the rest of the gastrointestinal tract in the fasting and digestive periods through complex neurohormonal mechanisms that include the vagus and splanchnic nerves and the hormone CCK as the major actors. During the fasting state the steady hepatic secretion of bile is mostly diverted toward the cystic duct and gallbladder where is stored and concentrated because of the sphincter of Oddi resistance. In this period a small fraction of bile leaks into the duodenum during the diastolic phase of the sphincter of Oddi phasic contractions and during the phase II of the migrating motor complex when there is slight gallbladder contraction. During the digestive period the gallbladder contracts emptying most of its contents, and bile is transported to the duodenum through the cystic and common bile ducts flowing through a relaxed sphincter of Oddi and duodenum. In the duodenum and jejunum bile salts participate in the digestion and absorption of fats (triglycerides, $\mathrm{Ch}$ and phospholipids, and liposolubles vitamins). Then bile salts are transported to the terminal ileum where are mostly recycled as part of the enterohepatic circulation by an active transport mechanism present in the epithelial cells of the terminal ileum.

\section{Chronic and Acute Cholecystitis}

3.1. Pathogenesis. The most common cited hypothesis in the pathogenesis of chronic and acute cholecystitis is that caused by obstruction of the cystic duct from small and medium sized gallstones that migrate from the gallbladder or in the case of large gallstones that they intermittently obstruct the neck of the gallbladder. However, this hypothesis is not supported by clinical and histological human studies or by experimental obstruction of the cystic duct in normal animals. Although occasionally gallstones are found in the cystic duct it is unclear whether these stones are actually obstructing the bile flow. A carefully conducted study in patients with acute cholecystitis in which the gallbladder was subjected to minimal manipulation, gallstones were found in the cystic duct in only $12.3 \%$ of patients examined during the surgical procedure [40].

Cholecystographic studies in patients with acute cholecystitis using technetium 99m-labeled HIDA, PIPIDA, or DISIDA have been used to support this hypothesis. The failure to visualize the gallbladder in patients with acute cholecystitis has been interpreted as due to obstruction cystic duct. This finding is present in patients with acute cholecystitis confirmed clinically and pathologically in up to $97 \%$ patients [41]. However, other explanations for this failure are more likely that (a) obstruction of the cystic duct could be due to the extension of the acute inflammation and edema from the gallbladder, or (b) an atonic gallbladder impedes the entry of the bulk of the isotope-labeled agent because it is filled with inflammatory secretions. Moreover, the acutely inflamed gallbladder may not be able to distend passively because of edema or actively because of a defective relaxation that have been shown to be present in gallbladders with lithogenic bile with high $\mathrm{Ch}$ concentrations [42]. 
The hypothesis of cystic duct obstruction is further challenged by the presence of cholecystitis associated only with lithogenic bile (acalculous gallbladder) or with a single large stone several times bigger than the typical diameter of the lumen of the cystic duct. It is unlikely that such large stones would cause recurrent episodes of obstruction by blocking the gallbladder neck. Moreover the occurrence of acute inflammation superimposed on a chronically inflamed or atrophic fibrotic gallbladder has been difficult to explain because it would imply recurrent episodes of cystic duct obstruction. It is more likely that the development of acute inflammation that is due to the progression from a chronic process had been in place long before. Such gallbladders frequently show mucosal thickening, hypertrophic muscle layers, and macrophage infiltration of the lamina propria. Chronic cholecystitis also is frequently seen histopathologically in the absence of gallstones. They occur in morbidly obese patients who have lithogenic bile without gallstones. These gallbladders have mucosal abnormalities consistent with chronic cholecystitis compared to the normal mucosa in nonobese subjects $[43,44]$.

Moreover the hypothesis of cystic duct obstruction has not been able to propose potential factors that could induce the inflammatory process. It has been suggested that gallbladder distension due to increasing amount of fluid in the lumen could lead to ischemia. However, these fluids are due to secretions from an already inflamed gallbladder. Some of the proposed proinflammatory agents that have been suggested are cellular mediators of inflammation such as lysolecythin and platelet activating factors secreted by epithelial cells already subjected to oxidative stress [45]. There is absence of histological and functional abnormalities in gallbladders with black pigment stones [46]. The mucosa of gallbladders containing pigment stones shows no evidence of chronic cholecystitis and no adenomatous hyperplasia or RokitanskyAschoff sinuses. These histological features are commonly found in gallbladders containing $\mathrm{Ch}$ stones. In contrast to the impaired contraction of gallbladders with Ch stones the contraction of muscle cells from gallbladders with pigment stones is not different from that observed in muscle preparations from normal gallbladders [47]. Although it has been reported a slight reduction of postprandial emptying in some patients with gallbladders with black pigment stones this functional impairment was likely due to a concurrent delayed gastric emptying that occurs in patients with thalassemia. Most of the patients included in this study suffered with this hematological disease [48].

Animal experiments do not support cystic duct obstruction as the initial event in the development of acute cholecystitis. Cystic duct ligation in prairie dogs does not cause cholecystitis unless concentrated bile is injected in the obstructed gallbladders [49]. Daily infusions of sterile fresh bile have to be introduced into ligated gallbladders of dogs for these animals to develop acute cholecystitis [3]. In contrast, animals fed lithogenic bile reproduce the epithelial and muscle abnormalities that are present in patients with chronic cholecystitis (Figure 1). These high concentrations of bile $\mathrm{Ch}$ inflict damage to gallbladder epithelial and muscle cells [50]. Rabbits treated with $1 \%$ dihydrocholesterol show evidence
Pathogenesis of chronic cholecystitis

(1) Role of lithogenic bile with high Ch concentrations

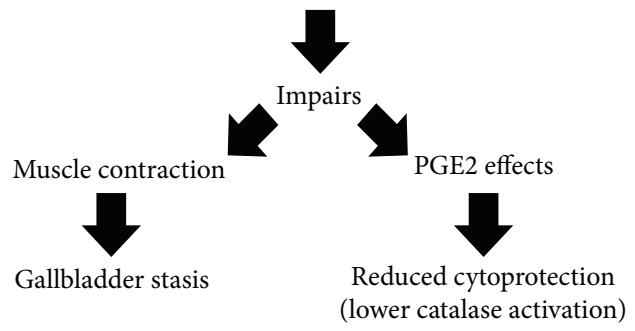

FIGURE 1

of epithelial cell proliferation in the initial stages of this process even before gallstones develop [51, 52]. The increase in proliferative activity preceding the formation of gallstones is another indication that these abnormalities are unrelated.

These data, therefore, suggest that both gallstones and abnormalities of the gallbladder mucosa and muscle are caused by lithogenic bile with excessive Ch concentrations. They develop independently of each other, even though they may be detected simultaneously in symptomatic patients. Ch diffuses through the gallbladder wall and is taken up by epithelial cells, macrophages in the lamina propria (cholesterolosis) and incorporated in the plasma membrane of muscle cells [53]. The rates of $\mathrm{Ch}$ diffusion through the mucosa appear to depend on its gallbladder bile concentrations [50]. Epithelial cells exposed to lithogenic bile with excess Ch increase PGE2 levels that stimulate water and mucus secretion before gallstones are formed [54, 55]. PGE2 stimulates mucin secretion by activating camp creating a thick mucus layer that frequently covers the mucosa of gallbladders with chronic cholecystitis [56]. The increased levels of this prostaglandin also are likely to be responsible for the mucosal hyperplasia, Rokitansky-Ashoff sinuses, and gastric and intestinal metaplasia [52, 57]. These abnormalities are frequently present in gallbladders with chronic inflammation [50]. Moreover these gallbladders also show macrophages in the lamina propia even in the absence of gallstones. Animal experiments show the effects of feeding lithogenic bile with excess $\mathrm{Ch}$ on gallbladder muscle cells. The muscle contraction induced by CCK- 8 is impaired in prairie dogs fed a lithogenic diet compared to muscle cells from animals fed a regular chow $[58,59]$. This impaired contraction is due to higher uptake of $\mathrm{Ch}$ by muscle cells. Similar abnormalities are present in the plasma membranes of muscle cells of human gallbladders with $\mathrm{Ch}$ stones. They also have higher levels of Ch than muscle cells from gallbladders with pigment stones.

Most of the $\mathrm{Ch}$ in the plasma membrane is found in caveolae [60]. Under normal and pathological conditions cellular influx and efflux of Ch take place through these caveolae [61]. These domains are rich in $\mathrm{Ch}$ bound to caveolin proteins. In addition to transporting $\mathrm{Ch}$ across membranes, caveolin proteins bind and help to internalize receptor- $\mathrm{G}$ protein complexes into the cytosol. Agonist activation of receptors leads to their coupling to specific $G$ proteins and then transferred to caveolae domains where they bind to caveolin proteins. These receptor-G protein complexes then phosphorylate caveolin 
proteins utilizing specific tyrosine kinases [62]. The phosphorylation of caveolin proteins makes possible the transfer of caveolin protein-receptor-G protein complexes to endosomes, organelles designed to recycle receptors back to the plasma membrane, so they can become available for further agonist activation. However, high Ch levels in the caveolae inhibit tyrosine kinases phosphorylation of caveolin proteins thereby blocking the internalization of these receptors and their recycling to the plasma membrane [62]. This inhibition leads to sequestration of receptors and caveolin proteins in the caveolae resulting in fewer receptors returning to the plasma membrane. The lower number of CCK-1 receptors explains the reduced binding of ${ }^{121-}$ I-CCK- 8 to plasma membranes of muscle cells from gallbladders with Ch stones compared to those from gallbladders with "black" pigment stones that have normal or even subnormal concentrations of $\mathrm{Ch}$ [63]. The lower receptor binding and weaker muscle response are not unique to CCK-1 receptors, since others are equally affected including cholinergic receptors that are internalized through these domains. In contrast, receptors internalized through clathrin-coated pit pathways like deltaopiate and erythromycin receptors express normal muscle responses. The finding that the clathrin pathway has low levels of Ch explains why erythromycin causes a normal contraction and emptying in gallbladders with Ch stones [62].

These pathological effects of high levels of $\mathrm{Ch}$ in the plasma membrane were experimentally demonstrated in isolated gallbladder muscle cells from humans and guinea pigs treated with $\mathrm{Ch}$ rich or $\mathrm{Ch}$ free liposomes. Liposomes are phospholipids aggregates that can carry $\mathrm{Ch}$ that is easily exchanged with cellular phospholipid membranes. The exchange is passive, and its direction is dependent on the $\mathrm{Ch}$ gradient between liposomes and plasma membranes. Ch free liposomes remove $\mathrm{Ch}$ from membranes of muscle cells from gallbladders with $\mathrm{Ch}$ stones that have high $\mathrm{Ch}$ levels [42]. In contrast, Ch diffuses from $\mathrm{Ch}$ rich liposomes to muscle cells from gallbladders with pigment stones that have normal levels of $\mathrm{Ch}$. This Ch exchange correlates with the magnitude of muscle contraction induced by CCK- 8 . There is a significant increase in the magnitude of contraction of muscle cells from gallbladders with $\mathrm{Ch}$ stones after incubation with $\mathrm{Ch}$ free liposomes, which removed the excess $\mathrm{Ch}$ from the plasma membranes. The opposite occurs when normally contracting gallbladder muscle cells from human or guinea pigs are incubated with $\mathrm{Ch}$ rich liposomes. These cells acquire abnormal concentrations of $\mathrm{Ch}$ and develop a weaker contraction in response to CCK-8. High Ch levels only affect membrane receptors since the pathways that mediate the contraction of gallbladder muscle cells distal to them are normal. These cells contract normally when stimulated with GTP $\gamma$ S, the $G$ protein activator or inositol triphosphate that bypasses receptors and $\mathrm{G}$ proteins to activate calmodulin [64].

Moreover, high levels of membrane Ch equally affect the muscle relaxation. The relaxation of muscle strips from gallbladders with $\mathrm{Ch}$ stones induced by receptor dependent agonists such as isoproterenol or VIP was lower than that induced in muscle strips from gallbladders with black pigment stones. However, there was no difference in the magnitude of relaxation between these two types of muscle strips induced by nitric oxide or 8-bromo-cAMP that bypasses membrane receptors [65]. Thus the effects of high levels of membrane $\mathrm{Ch}$ that impair muscle contraction and relaxation are confined to the plasma membrane receptors.

The effects of high concentrations of $\mathrm{Ch}$ in the plasma membrane of gallbladder muscle cells also affect calcium without involving potassium channels. High Ch levels also suppress the voltage-activated $\mathrm{Ca} 2+$ current in these cells [66]. Activity of these $\mathrm{Ca} 2+$ channels is responsible for the spontaneous rhythmic action potentials in gallbladder smooth muscle cells [67], and this Ca2+ entry is necessary for maintaining intracellular Ca2+ stores [68]. Interestingly, the $\mathrm{K}+$ channels in gallbladder smooth muscle are unaffected by increased concentrations of membrane $\mathrm{Ch}$ suggest that in contrast to $\mathrm{Ca} 2+$ channels in gallbladder smooth muscle $\mathrm{K}+$ channels may not be located in the caveolar membranes and are therefore not susceptible to the Ch effects.

High levels of Ch also affect small intestinal muscle cells that in turn contribute to the development of cholecystitis. Lithogenic diets fed to C57L mice impair the contractility of muscle cells of the small bowel resulting in slower intestinal transit. The slow transit generates in the distal small intestine the secondary bile acid deoxycholic acid [69] and greater $\mathrm{Ch}$ absorption. They both increase the number of inflammatory cells in the lamina propria and muscle hypertrophy of the gallbladder. These abnormalities take place four weeks after they are fed a lithogenic diet and before gallstones are formed [70]. These abnormalities do not occur when these mice are pretreated with maximal doses of ezetimibe that blocks the intestinal absorption of Ch.

Normal gallbladders tolerate physiological concentrations of hydrophobic bile salts. However, in the presence of lithogenic bile with high concentrations of $\mathrm{Ch}$ or after obstruction of the common bile duct these bile salts can damage the epithelial and muscle cells by increasing the levels of oxidative stress $\left(\mathrm{H}_{2} \mathrm{O}_{2}\right)$ and lipid peroxidation [51, 71] (Figure 2). Guinea pigs develop an acute inflammatory reaction following ligation of the common bile duct within 3 days [72]. Pretreatment of these animals for 2 weeks with the hydrophilic bile acid URSO prior to the ligation of the common bile duct prevents the development of acute cholecystitis. In contrast, acute cholecystitis was far more severe when they were pretreated with a hydrophobic bile acid chenodeoxycholic acid for two weeks prior to the common bile ligation compared to guinea pigs that received no treatment during this period of time.

The mechanism whereby URSO exerts this therapeutic effect was examined in epithelial and muscle cells. The lipid peroxidation in the epithelial cells and mucosal secretion of mucin and water secretion induced by treatment with hydrophobic bile salts alone were prevented by pretreatment with URSO [73]. Pretreatment with URSO also prevented the impaired muscle contraction induced in isolated muscle cells treated with hydrophobic bile salts [74]. Hydrophobic bile salts inhibit smooth muscle contraction by acting on Gprotein coupled BAR1 receptors, activating KATP channels [74] and high detergency properties. They increase oxidative stress in muscle cells in vitro and in vivo. URSO reduced the 
Pathogenesis of chronic cholecystitis

(2) Role of hydrophobic bile salts

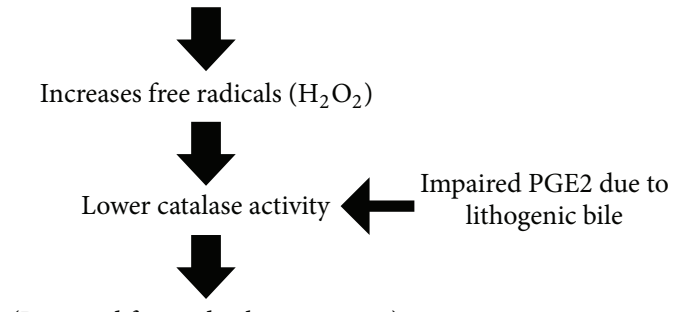

(Impaired free radical inactivation)

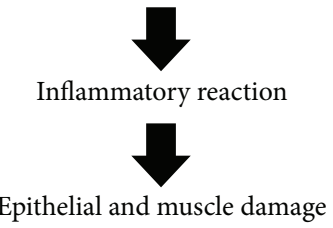

FIGURE 2

levels of free radicals and cytoprotection response in gallbladder muscle cells compared to muscle cells incubated with chenodeoxycholate alone [75]. Other mucosal tissues can be similarly affected by prolonged exposure to hydrophobic bile salts leading to esophagitis and gastritis.

The therapeutic effect of URSO treatment was demonstrated in patients with symptomatic gallbladders with $\mathrm{Ch}$ gallstones. URSO treatment for one month prior to surgery increased gallbladder muscle contractility and reduced the levels of membrane $\mathrm{Ch}$ and indices of oxidative stress [76]. URSO also improved the gallbladder inflammation decreasing the monocyte/macrophage, mast cell degranulation, granulocyte infiltrate, and COX-2 expression compared to placebo-treated patients. This short-term study is supported by a larger study performed in patients with symptomatic gallbladder stones. An 18-year-old study demonstrated that URSO treatment reduced the incidence of biliary pain and rates of cholecystectomy compared to untreated patients [77]. The positive effect of URSO occurred despite the persistence of gallbladder stones. The mechanism of URSO protection from the effects of hydrophobic salts in vivo is not completely known. Hydrophobic bile salts increase oxidative stress levels in gallbladder muscle cells in vitro causing impaired contraction. URSO prevents these deleterious effects on gallbladder epithelial and muscle cells by blocking the actions of hydrophobic bile salts at the cellular level [75] and by inhibiting the intestinal absorption of $\mathrm{Ch}$ [78].

The high levels of plasma membrane Ch also affect PGE2 receptors involved in cytoprotective functions. PGE2 is an autacoid released by cells but acting on their plasma membrane receptors that stimulate the activation of catalase. This enzyme inactivates free radicals (e.g., $\mathrm{H}_{2} \mathrm{O}_{2}$ ) keeping the levels of oxidative stress within normal levels, preventing lipid peroxidation and receptor damage [79]. There are no differences between the levels of PGE2 induced by oxidative stress $\left(\mathrm{H}_{2} \mathrm{O}_{2}\right)$ in muscle cells from gallbladders with $\mathrm{Ch}$ and with "black" pigment gallstones. However, the effects of exogenous PGE2 or of oxidative stress $\left(\mathrm{H}_{2} \mathrm{O}_{2}\right)$ on catalase activity and degree of free radical inactivation are reduced in muscle cells from gallbladders with Ch gallstones compared to muscle cells from gallbladder with pigment stones [80]. These findings suggest that high levels of plasma membrane Ch impair cytoprotective responses to exogenous and endogenous PGE2 because, as with CCK receptors, fewer PGE2 receptors are available for stimulation.

Healthy gallbladder cells, therefore, protect themselves from aggressive actions of hydrophobic bile salts by utilizing cytoprotective mechanisms that include the actions of PGE2 and motility mechanisms that empty the gallbladder bile regularly [79]. Both protective mechanisms are affected by supersaturated levels of $\mathrm{Ch}$ rendering the mucosa and muscle layers vulnerable to hydrophobic bile salts. In the initial stages of the inflammatory process these bile salts damage unprotected receptors, such that they are stimulated by exogenous agonists. CCK-1 receptors of the smooth muscle are initially damaged impairing muscle contraction. Some receptors remain unaffected because they are protected by the release of autacoids such as the case of PGE2 receptors protected by the cellular release of PGE2. However, high levels of membrane $\mathrm{Ch}$ affect even these receptors. These effects were clearly demonstrated in isolated gallbladder muscle cells treated with $\mathrm{Ch}$ rich or $\mathrm{Ch}$ free liposomes [80]. There is a normal response to the actions of PGE2 on muscle cells from gallbladders with pigment stones or muscle cells from gallbladders with $\mathrm{Ch}$ stones treated with $\mathrm{Ch}$ free liposomes. In contrast, the effects of PGE2 are impaired in normal muscle cells incubated with $\mathrm{Ch}$ rich liposomes. These findings suggest that lithogenic bile with high $\mathrm{Ch}$ concentrations affects membrane receptors other than the CCK-1 receptors impairing the gallbladder's ability to protect itself against hydrophobic bile salts by reducing gallbladder contractility and emptying and impairing PGE2 dependent cytoprotective mechanisms that inactivate free radicals.

The prevalence of lithogenic bile and gallbladder disease is higher in females than in males suggesting that sex hormones may be involved in the pathogenesis of cholecystitis. Most of the studies have focused on the actions of progesterone since this hormone impairs gallbladder contractility through its genomic-mediated actions that downregulates $\mathrm{G}$ proteins $(\mathrm{Gq} / 11$ and $\mathrm{Gi3})$ that mediate agonist-induced contraction [81]. Progesterone impairs the contraction induced by CCK- 8 in normal gallbladder muscle cells, but it does not affect muscle cells from gallbladders that contain $\mathrm{Ch}$ stones or normal muscle cells treated with $\mathrm{Ch}$ rich liposomes. Like $\mathrm{Ch}$ progesterone is transported across the plasma membrane by caveolin proteins. Experimentally, treatment with $\mathrm{Ch}$ rich liposomes blocks the entry of ${ }^{3} \mathrm{H}$-progesterone into the plasma membrane of normal muscle cells compared to cells treated with $\mathrm{Ch}$ free liposomes [82]. Ch inhibits entry of this hormone into the plasma membrane possibly because of stronger hydrophobic interactions of $\mathrm{Ch}$ with the hydrophobic binding sites of caveolae proteins. Estrogens are likely to play a more important role in the pathogenesis of gallbladder disease because they increase biliary secretion of Ch. Estrogen receptor alpha, but not beta, plays a major role in 17-beta-estradiol-induced murine Ch gallstones [83]. 
Increases in estrogen and progesterone levels during pregnancy explain the gallbladder hypomotility, stasis, and Ch supersaturated bile.

Other hormones may also increase the incidence of gallbladder disease. Octreotride is one hormone that causes gallbladder hypomotility. Patients treated with octreotride for long periods of time have an increased incidence of cholelithiasis. It is likely that this hormone causes gallbladder disease by increasing bile saturation with $\mathrm{Ch}$. It causes hyperabsorption of $\mathrm{Ch}$ from both dietary and biliary sources by inducing hypomotility of the small intestine [84]. This slow intestinal transit also leads to the formation of more secondary and therefore more hydrophobic bile salts such as deoxycholate conjugate. Gallbladder hypomotility and bile stasis tend to promote the formation of macroscopic gallstones from Ch crystals in bile because bile is retained for longer periods of time in the interdigestive and postprandial states. However, unless the bile is supersaturated with $\mathrm{Ch}$ there is no evidence that impaired motility per se leads to gallbladder inflammation [85].

The factors that contribute to the progression from chronic to acute cholecystitis are not known. Most cases of acute cholecystitis develop in patients whose gallbladders already have evidence of chronic cholecystitis as determined by presence of $\mathrm{Ch}$ gallstones and histology consistent with chronic inflammation. These chronic changes are characterized by mucosal and muscle hypertrophy and thickened serosal layer. The widely accepted assumption that acute cholecystitis is triggered by gallstone obstruction of the cystic duct is not supported by human and animal studies (see the section on the pathogenesis of chronic cholecystitis associated with lithogenic bile with excess $\mathrm{Ch}$ ). However, there are risk factors known to increase the incidence of this progression. There is an increase in the incidence of acute cholecystitis with aging (20\% of men and $35 \%$ of women by age 75) and diabetes conditions that are associated with diminishing immunity. The incidence of acute cholecystitis in patients with diabetes with chronic cholecystitis as determined by the presence of gallstones is as high as $13-16 \%$ [ 86 , 87]. Organ transplantation and chemotherapy are also known to increase this progression. There is a higher incidence of acute cholecystitis with or without gallstones in conditions that are known to affect the immune response such as leukemia, chemotherapy and following major surgery and other debilitating conditions. Although research studies are needed in this area it is possible to speculate that reductions in local or systemic immunity may facilitate this progression.

In conclusion, the data obtained from the abovementioned human and animal studies strongly suggest that cholecystitis develops in the presence of lithogenic bile with high $\mathrm{Ch}$ concentrations that creates a permissive environment allowing hydrophobic bile salts to increase the levels of oxidative stress and initiate the inflammatory process. This inflammatory process requires the continuous entry of hydrophobic bile salts into the diseased gallbladder.

3.2. Chronic Cholecystitis: Clinical Symptoms. Patients with chronic cholecystitis may be asymptomatic or complain of recurrent episodes of epigastric and right upper quadrant pain that frequently radiates around the waist and toward the scapula. The pain is of moderate-to-severe intensity and is not postprandial but frequently nocturnal. It does not occur daily and tends to occur every two to three weeks. Usually the diagnosis is made by ultrasonography. This test can detect the presence of gallstones and thickening of the gallbladder wall. Laboratory studies are normal [88].

Although gallstones are frequently asymptomatic they are blamed for a variety of upper gastrointestinal symptoms because they are easily detected in gallbladders by imaging studies. Gallstones are commonly believed to be responsible for nonspecific gastrointestinal symptoms due to chronic dyspepsia, gastroparesis, and even irritable bowel syndrome. Patients with these functional conditions usually complain of daily upper gastrointestinal symptoms that are frequently postprandial and brought about by fatty foods or large meals. These patients complain of epigastric distress, nausea, and bloating. Cholecystectomy does not improve these complaints even though pathological studies may reveal gallstones and histological evidence of chronic cholecystitis. Several studies, including autopsy studies, have shown that gallstones may remain asymptomatic for prolonged periods of time. In a prospective Italian study most patients with asymptomatic gallstones remained symptom free for the entire 8-year followup period [89].

3.3. Risk Factors. The incidence of gallstones and inflammatory gallbladder disease is high in the Western hemisphere particularly in the native Indian population of North and South America. The epidemiology and natural history of this disease in Pima Indians suggest that genetic factors play an important role. The incidence of gallbladder disease in this Indian female population of New Mexico is as high as $40 \%$ by the age of 85 [90,91]. In addition Ch lithogenic genes appear widely spread among Chilean Indians and Hispanics. These genes could determine the early formation of gallstones and explain the high prevalence of gallbladder diseases among some South American populations [92]. The incidence of gallbladder disease in females is particularly higher in obese and diabetic patients compared to controls. In contrast there are no differences in the incidence of gallbladder disease in males between diabetics and nondiabetics. The higher incidence of gallbladder disease in females suggest that sex hormones are involved in the pathogenesis of this disease with estrogens playing the most important role (see "pathogenesis").

3.4. Diagnosis. A right upper quadrant ultrasound is the diagnostic test of choice in patients with chronic cholecystitis. This test is performed in patients with biliary pain usually described as epigastric and right upper quadrant pain. Ultrasonography detects gallstones or biliary sludge [93]. Gallstones are usually but not always the imaging sign of lithogenic bile with excess $\mathrm{Ch}$ in the gallbladder. Chronic cholecystitis can be present in the absence of gallstones. It is not unusual to find histological evidence of chronic cholecystitis in acalculous gallbladders from obese patients. Indirect evidence in support of this diagnosis can be obtained by performing a HIDA scan with a provocative test with CCK-8. 
Patients with chronic cholecystitis due to lithogenic bile with high Ch concentrations have impaired motility and emptying compared to normal subjects or patients with black pigment stones [14]. This test cannot distinguish between acalculous chronic cholecystitis and functional gallbladder disease. The final diagnosis can be reached only after careful histological examination of the gallbladder using specific COX-2 antibodies that can detect the presence of activated macrophages containing up regulation of COX-2. These cells should be absent in patients with functional gallbladder disease.

3.5. Treatment. Laparoscopic cholecystectomy is the treatment of choice for patients with chronic cholecystitis and recurrent episodes of moderate-to-severe biliary pain. However, patients with occasional mild-to-moderate biliary pain with gallbladder stones may not require immediate treatment, since the pain may not recur. Similar observations were made in an 8-year prospective study that enroll patients without or mild-to-moderate symptoms with gallbladder stones [89].

Significant technical improvements in laparoscopic surgery and greater surgical experience have markedly reduced the incidence of complications. This type of procedure should be performed when surgeons are able to identify the vascular and biliary duct structures. In the presence of adhesions, however, the common bile and cystic ducts may not be easily recognized. If surgeons are unable to fully identify these structures the procedure should be converted to open cholecystectomy.

These surgical procedures, in patients without significant systemic risks, have a very low incidence of surgical complications arising mostly from unrecognized biliary tract anomalies. It is estimated that about $10 \%$ of patients may have one or more biliary duct anomalies, but not all of them are difficult to recognize during surgery. Common variants of the main hepatic biliary branching is the so-called triple confluence, which is an anomaly characterized by simultaneous emptying of the right posterior duct, right anterior duct, and left hepatic duct into the common hepatic duct [94]. In patients with this variant, the right hepatic duct is virtually nonexistent. Other common anatomic variants of the branching of the biliary tree involve the right posterior duct and its fusion with the right anterior or left hepatic duct. As mentioned earlier, the right posterior duct normally passes posterior to the right anterior duct and joins it from the left to form the right hepatic duct, which then forms a junction with the left hepatic duct to form the common hepatic duct. Drainage of the right posterior duct into the left hepatic duct before its confluence with the right anterior duct is the most common anatomic variant of the biliary system. Moreover, several less common and usually more complicated anatomic variations of the bile ducts have been described and consist of both aberrant and accessory bile ducts. In a clinical context, familiarity with these entities is important because an aberrant bile duct is the only bile duct draining a particular hepatic segment, whereas an accessory one is an additional bile duct draining the same area of the liver. Failure to recognize some of these bile duct anomalies can result in bile leaks causing inflammation of the peritoneal membranes (bile peritonitis). These leaks are treated by placing stents through an endoscopic retrograde cholagiopancreatography (ERCP). They can stop these leaks that arise from the common bile or cystic ducts.

Although surgery is the treatment of choice for patients with chronic cholecystitis, medical treatment with URSODIOL is a potential alternative in elderly patients with high surgical risks and recurrent biliary pain due to chronic cholecystitis. The initial impetus for the use URSO in patients with chronic cholecystitis was to dissolve gallstones, criteria that limited the eligibility to this treatment to about 20 to 25\% of patients [95]. However, in view of our changing concepts of the pathogenesis of cholecystitis the therapeutic objective should be to treat gallbladders with lithogenic bile with high $\mathrm{Ch}$ concentrations with URSO to improve the ability of the gallbladder to tolerate the aggressive actions of hydrophobic bile salts (please see the pathogenesis of chronic cholecystitis) and by blocking their actions at their cellular level. However, there are only few candidates that qualified to receive this treatment. Therefore, the size of the gallstones should not be criteria for exclusion. The effectiveness of this treatment was examined by comparing the results of treating patients from 50 to 70 years old with typical biliary pain with URSO or elective cholecystectomy. Patients were included in this study if they had noncalcified gallstones of less $20 \mathrm{~mm}$ in diameter and a functioning gallbladder. This clinical trial found that URSO was clinically advantageous and less expensive than surgical treatment in older patients with surgical risks. Expected lifetime costs of ursodiol range from \$300-400 more than surgery for 50 -year-olds to $\$ 700-1,000$ less than surgery for 70 -year-olds [96]. This study is supported by an 18 -year study that compared URSO treatment with no treatment in a large number of patients with symptomatic gallbladder stones. URSO was significantly more effective than no treatment in controlling biliary pain and preventing the need for cholecystectomy [77]. Medical treatment, however, may not be effective in patients with more advanced chronic cholecystitis.

\section{Acute Cholecystitis}

4.1. Clinical Symptoms. Chronic cholecystitis is the most common risk factor in acute cholecystitis. These patients usually complain of sudden onset of severe pain that is frequently associated with nausea in $90 \%$ and vomiting in 50\% of the cases. Physical examination reveals epigastric, right upper quadrant tenderness, and positive Murphy sign, and in severe cases patients may have rebound tenderness. However, before this diagnosis can be entertained clinicians need to rule out other acute abdominal conditions that include acute appendicitis particularly with a retrocecal appendix, acute pancreatitis, localized perforated peptic ulcer, intestinal perforation, or ischemia. These clinical entities have similar demographic and risk factors patterns. These patients complain of acute abdominal pain, nausea, and vomiting, and physical examination reveals abdominal tenderness that can be localized or diffuse and marked reduction in bowel sounds.

4.2. Diagnosis. Laboratory studies in patients with acute cholecystitis have leukocytosis of 10,000 to 15,000 per cc. Imaging studies are necessary to confirm a suspected clinical 
diagnosis of acute cholecystitis. Most clinicians advocate the ultrasound, as the initial imaging test that is currently the most common diagnostic test performed in these patients. This test can detect the presence of gallstones in $98 \%$ of the cases and in a large proportion of these patients can demonstrate other abnormalities consistent with acute cholecystitis such as gallbladder wall thickening, abnormal appearance of the wall with sonolucent areas caused by subserosal edema or hemorrhage, and pericholecystic fluid. Gallbladder walls thicker than 2 to $4 \mathrm{~mm}$ are considered abnormally thickened. Pericholecystic fluid represents inflammatory exudates, but occasionally it may be due to localized perforations. However, some of these findings may not indicate acute cholecystitis if there is evidence of severe hypoalbuminemia or ascites, which may also cause diffuse edema of the small intestine and colon.

Nevertheless, this test has a sensitivity and specificity of 90 to $95 \%$. Radiologists try to improve the accuracy of the diagnosis of acute cholecystitis by performing the ultrasonographic Murphy sign. This test is positive when the transducer is able to demonstrate that the tenderest point of the abdominal wall on deep inspiration is present directly over the gallbladder position. This maneuver is very useful although not specific, since inflammatory conditions of adjacent organs can mimic this tender point.

Although ultrasonography is less specific than cholescintigraphy it can provide important information on the state of other abdominal organs such as the liver, common bile duct, and pancreas. It can also recognize some of the more serious complications of acute cholecystitis such as empyema, pericholecystic abscess, and perforation. Moreover in contrast to cholescintigraphy it can examine the gallbladder in patients with hyperbilirubinemia, and it does not expose patients to ionizing radiation. This is the reason why it is the diagnostic test of choice in pregnant women and in children.

If after the ultrasound examination this diagnosis is still inconclusive, physicians advocate performing a cholescintigraphy with radio labeled HIDA, PIPIDA, or DISIDA [41]. Visualization of the gallbladder normally occurs within 30 minutes after the injection of these radio labeled technetium analogues. Failure to visualize the gallbladder within 60 minutes is consistent with the diagnosis of acute cholecystitis. This test has been reported to be $95 \%$ sensitive and specific in diagnosing acute cholecystitis. The failure to visualize the gallbladder has been interpreted as due to gallstone obstruction of the cystic duct. However, other interpretations are more likely such extension of the inflammatory process to the cystic duct or gallbladder filled with inflammatory secretions (see the discussion of this issue in the pathogenesis of the chronic and acute cholecystitis). This test has a false negative rate of $0.5 \%$ when the gallbladder is seen within 30 minutes after the administrations of the isotope. Gallbladder filling within 30 to 60 minutes is less reliable in excluding acute cholecystitis with the false negative rates of $20 \%$. A false positive test is more common and occurs when it fails to show the gallbladder in the absence of acute cholecystitis. It is estimated that the gallbladder does not fill within $1 \mathrm{~h}$ in 5 to $10 \%$ of patients in the absence of acute cholecystitis.
If this diagnosis is suspected in the context of symptoms and signs of an acute abdomen, emergency room physicians proceed to perform a CAT scan of the abdomen. This test also should be performed when the gallbladder ultrasound is inconclusive [97]. The other advantage of this test is that the quality of the CAT scan is not affected by air or obesity. However, it may miss some gallstones if they have the same radiological density of the gallbladder bile. It is estimated that the CAT scan can only detect $79 \%$ of gallstones. The over all positive predictive value for CAT scans for acute cholecystitis is not much different from that for ultrasound. The advantage of the CAT scan is that it can detect other pathological processes involving organs other the gallbladder. CAT scan also misses fewer cases than ultrasound because the ultrasound sensitivity can be influenced by the patient characteristics and reader experience in interpreting the images.

4.3. Treatment. Once the diagnosis of acute cholecystitis is made, patients should be given nothing by mouth and treated with intravenous fluids. Pain should be controlled with meperidine or Demerol, since this opiate does not increase sphincter of Oddi pressures. Most surgeons advocate the use of antibiotics particularly in moderate-to-severe cases of acute cholecystitis and in the presence of complications such as perforations and pericholecystic abscess. The use of prophylactic antibiotics is necessary if surgery is contemplated or if choledocholithiasis is being considered.

Laparoscopic cholecystectomy should be performed as soon as possible, usually within the first $48-72 \mathrm{~h}$ of the onset of symptoms unless there are serious contraindications to the surgical procedure such as severe emphysema or congestive heart failure. However, several studies showed that there are no differences in the morbidity and mortality between early defined as having the surgical procedure within seven days from the onset of the symptoms versus delayed cholecystectomy performed between 8 and 16 weeks [98]. In most of these studies the elderly was excluded and therefore is not known whether this approach applies to these patients. It is also not clear whether diabetic patients also should be treated shortly after the onset of symptoms. Conversion to open cholecystectomy is an absolute indication when the vascular structures and biliary ducts cannot be conclusively identified during the laparoscopic procedure because of extensive inflammatory reaction, fibrosis surrounding the gallbladder, or suspected unusual anomalies of the biliary ducts.

The frequency of acute cholecystitis in pregnant women ranges between 0.08 and 0.8 per 1000 cases. This incidence may be slightly higher that in nonpregnant women. There is no consensus whether surgery or conservative treatment is preferable. Conservative treatment is recommended because of the high risk of fetal loss associated with general anesthesia particularly during the first trimester. The Mayo Clinic experience differs from this recommendation, since in their series there was only one abortion among 20 pregnant patients treated with cholecystectomy in the first trimester. In general conservative treatment is recommended in the first and third trimester. In the latter trimester the enlarged uterus limits the laparoscopic access to the gallbladder [99]. 


\section{Functional Gallbladder Disorders}

Functional disorders of the gallbladder are poorly defined motility abnormalities that may be initially caused by metabolic abnormalities or by a primary motility disorder. Gallbladder dysfunction produces patterns of pain similar to those of chronic cholecystitis [100]. The consensus arrived at the Rome III conference suggested that the diagnosis of gallbladder dysmotility should be based on symptoms characterized by episodes of moderate-to-severe steady pain located in the epigastrium and right upper abdominal quadrant that last at least 30 minutes. These symptoms are usually not postprandial or daily. This clinical entity should be considered after gallstones, and other structural abnormalities have been excluded. Gallbladder ultrasound can be useful in that it can rule in or out the presence of lithogenic bile with microcrystals. This diagnosis should then be confirmed by a decreased gallbladder ejection fraction determined by a provocative cholescintigraphy with intravenous cholecystokinin and after resolution of recurrent biliary pain after a cholecystectomy. The studies that support these conclusions were arrived without considering the effects of lithogenic bile with excess $\mathrm{Ch}$ on gallbladder motility and on chronic inflammation. Most of these studies reported the diagnosis of functional gallbladder disease without examining whether or not they contain lithogenic bile and whether activated inflammatory cells were present in the gallbladder wall. Like the functional motility disorder gallbladders with lithogenic bile exhibit a lower ejection fraction after CCK or meal stimulation. However, histological examination reveals the presence of activated macrophages consistent with chronic cholecystitis. These histological abnormalities should be ruled out before the functional diagnosis is established. Therefore the diagnosis of gallbladder dysmotility should be made in patients with biliary like pain, reduced ejection fraction by cholescintigraphy after CCK stimulation, normal gallbladder bile with absence of lithogenic bile with excess $\mathrm{Ch}$, and absence of inflammatory cells.

Summary and Future Perspectives. In the past 30 years we have learned a great deal about the pathogenesis of chronic cholecystitis a well-known precursor for the development of acute cholecystitis. There is increasing evidence that gallstones although important in the pathogenesis of bile duct complications do not play a significant role in the development of cholecystitis. Therefore, there is a need for clinical trials with URSO in patients that are not candidates for surgical treatment. Dissolution of gallbladder gallstones, although an important objective, should not be the sole criteria for whether URSO may be effective. This bile salt should be considered in patients with lithogenic bile with high $\mathrm{Ch}$ concentrations to lower the lithogenicity and block the actions of the hydrophobic bile salts.

\section{Sphincter of Oddi Dyskinesia}

Patients with sphincter of Oddi (SO) dyskinesia who complain of biliary-like symptoms usually recognized in the postcholecystectomy period. These patients with dysfunction of the bile duct sphincter have symptoms and signs suggestive of transient bile duct obstruction, and those of pancreatic sphincter of Oddi dysfunction are associated with elevation of pancreatic enzymes and even full-blown pancreatitis.

Patients with sphincter of Oddi dysfunction are evaluated with either quantitative choledochoscintigraphy and/or sphincter of Oddi manometry tests designed to objectively confirm this diagnosis. Although the initial investigation defined this functional entity by sphincter of Oddi manometry, later studies have shown that quantitative choledochoscintigraphy is as useful as sphincter of Oddi manometry in establishing this diagnosis. An abnormal transit time from the hilum to the sphincter of Oddi/duodenum by quantitative choledochoscintigraphy is as or even more useful than sphincter of Oddi manometry in the diagnosis of sphincter of Oddi dyskinesia, since a large percentage of patients with abnormal transit time have improved after sphincter of Oddi sphincterotomy [101]. Patients with sphincter of Oddi dyskinesia I and II have an excellent symptomatic response to sphincterotomy whether they were selected on the basis of an abnormal transit time by quantitative choledochoscintigraphy or by sphincter of Oddi manometry. The former has the advantage of not being invasive and without significant complications. However, if the sphincter of Oddi manometry is required to further confirm this diagnosis and define the type of sphincter of Oddi dyskinesia, the Rome III consensus suggested that these patients should be referred to an expert unit because of the high incidence of complications that occurs after this test. The Rome III consensus also concluded that this invasive test should be performed only in the presence of compelling clinical evidence and after noninvasive testing yielded negative findings. The Rome III committee recommended that the division of the biliary or pancreatic sphincters only be considered when patients have severe symptoms and meet the required criteria of sphincter of Oddi dyskinesia, and other diagnoses are excluded. Moreover, based on these and other studies there appear to be a close correlation between the results of quantitative choledochoscintigraphy and sphincter of Oddi manometry studies.

These patients have been grouped into three types depending on their laboratory and sphincter of Oddi findings. Patients with biliary type I sphincter of Oddi dyskinesia complain of biliary-like pain, have elevated liver function tests documented on two or more occasions, a dilated common bile duct with a corrected diameter equal to or greater than $12 \mathrm{~mm}$, and delayed contrast drainage from the common bile duct by endoscopic retrograde cholangio-pancreatography and basal pressures higher than $40 \mathrm{~mm}$ Hg. Type II patients complain of biliary-like pain and have only one or two of the previously mentioned criteria. Type III patients are characterized by recurrent biliary type pain but without laboratory or manometry abnormalities [102].

The incidence of complications in patients complaining of significant pain or developing pancreatitis following sphincter of Oddi motility is higher in patients with sphincter of Oddi dyskinesia than in patients with organic abnormalities of the common bile duct. These complications are even higher in patients with sphincter of Oddi dyskinesia Type III than in types I and II. The incidence of postmotility pancreatitis in 
these patients can be as high as $19.7 \%$. The reasons for the high incidence of complications is not entirely known, although there are data suggesting that higher rates of perfusion during the procedure is partially responsible for these complications [103]. Nonperfusion motility methods have been devised to study the sphincter of Oddi dyskinesia. This method probably should reduce the incidence of postmanometry pancreatitis.

Most of the patient' symptoms with type I dyskinesia respond to sphincterotomy compared to the symptomatic response to sham treatment. Some of these patients appear to have organic stenosis, since their high basal sphincter of Oddi pressures do not relax in response to CCK. Most of the patients with type II sphincter of Oddi dyskinesia also improve after sphincterotomy, but the percentage is lower than the therapeutic response observed in patients with type I dyskinesia. There is small group of patients with sphincter of Oddi dyskinesia with either Type I or II in whom the sphincter of Oddi contracts rather than relax in response to CCK [104]. This paradoxical response suggests sphincter of Oddi denervation because of the absence of nonadrenergic noncholinergic inhibitory neurons. Patients with type III sphincter of Oddi dyskinesia have biliarylike pain but have normal laboratory tests and sphincter of Oddi pressures. Most of these patient' symptoms do not respond to sphincterotomy raising the question whether the pain is caused by gastrointestinal functional disorders unrelated to the sphincter of Oddi. There is, however, one small and open label study that showed that in some patients with type III sphincter of Oddi dyskinesia the symptoms improved after botulinum toxin was injected in the papilla of Vater. It showed that $50 \%$ of patients had a temporary symptomatic improvement for of up to six months after treatment [105]. Botulinum toxin is known to block neural stimulation, particularly mediated by cholinergic neurons and sensory pathways $[106,107]$. This therapeutic response suggests that the pain may be due to an abnormality in the sensory pathways arising from this region. The results of the above-mentioned study, however, need to be confirmed by a larger double blind placebo clinical trial.

Most of these reports do not describe the gallbladder abnormalities of patients prior to undergoing a cholecystectomy, whether these patients had chronic or acute cholecystitis or whether they were calculus or acalculous. These data may be important because we do not know whether the original symptoms arose from the gallbladder, from the sphincter of Oddi, or from both. This knowledge also is important to explain the pathogenesis and nature of type I and perhaps of type II dyskinesia in which the abnormality may be of organic nature or sphincter of Oddi stenosis. It is conceivable that this type of sphincter of Oddi dyskinesia (or stenosis?) may be caused by the passage of gallstones through this segment resulting in trauma and subsequent sphincter fibrosis. Furthermore, a previous history of gallstones in patients with sphincter of Oddi dyskinesia could also explain the lopsided incidence of this condition in females compared to that of males.

In summary, a great deal of new knowledge has been acquired from a series of careful studies performed in patients with postcholecystectomy pain using sphincter of
Oddi manometry and/or choledochoscintigraphy as well as clinical trials that assessed the symptomatic response to Oddi sphincterotomy. However, further studies are needed to determine the nature of the dysfunction, whether in some patients the dysfunction may be due to organic stenosis and in others to neural abnormalities involving the motor or sensory innervation of the sphincter of Oddi.

\section{References}

[1] W. J. Dodds, W. J. Hogan, and J. E. Geenen, "Motility of the biliary system," in Handbook of Physiology: Gastrointestinal System. Volume Motility and Circulation, J. Wood and S. Schultz, Eds., chapter 28, pp. 1055-1101, Oxford University Press, New York, NY, USA, 1989.

[2] R. D. Odze and J. R. Goldblum, Eds., Surgical Pathology of the GI Tract, Liver, Biliary Tract and Pancreas, chapter 29, part 2, Saunders, Philadelphia, Pa, USA, 2009.

[3] J. Svanvik, C. A. Pellegrini, B. Allen, R. Bernhoft, and L. W. Way, "Transport of fluid and biliary lipids in the canine gallbladder in experimental cholecystitis," Journal of Surgical Research, vol. 41, no. 4, pp. 425-431, 1986.

[4] S. G. Corradini, W. Elisei, L. Giovannelli et al., "Impaired human gallbladder lipid absorption in cholesterol gallstone disease and its effect on cholesterol solubility in bile," Gastroenterology, vol. 118, no. 5, pp. 912-920, 2000.

[5] J. Behar and P. Biancani, "Motility of the biliary system," in Handbook of Physiology: Gastrointestinal System. Volume Motility and Circulation, J. Wood and S. Schultz, Eds., chapter 29, pp. 1055-1101, Oxford University Press, New York, NY, USA, 1989.

[6] K. Sonobe, T. Sakai, M. Sato, N. Haga, and Z. Itoh, "Control of gallbladder contractions by cholecystokinin through cholecystokinin-A receptors in the vagal pathway and gallbladder in the dog," Regulatory Peptides, vol. 60, no. 1, pp. 33-46, 1995.

[7] M. Cicala, E. Corazziari, D. Diacinti, D. Badiali, and A. Torsoli, "Effect of endogenous cholecystokinin on postprandial gallbladder refilling: ultrasonographic study in healthy subjects and in gallstone patients," Digestive Diseases and Sciences, vol. 40, no. 1, pp. 76-81, 1995.

[8] K. Shiratori, S. Watanabe, W. Y. Chey, K. Y. Lee, and T. M. Chang, "Endogenous cholecystokinin drives gallbladder emptying in dogs," American Journal of Physiology, vol. 251, no. 4, pp. G553-G558, 1986.

[9] D. F. Magee, S. Naruse, and A. Pap, "Vagal control of gall-bladder contraction," Journal of Physiology, vol. 355, pp. 65-70, 1984.

[10] M. Khoursheed, D. Krajci, M. A. Oriowo, E. Kadavil, E. K. Philip, and O. Thulesius, "Neurogenic control of the ovine gallbladder: ultrastructural and functional study," Digestion, vol. 59, no. 4, pp. 335-342, 1998.

[11] Q. Chen, K. Lee, Z. Xiao, P. Biancani, and J. Behar, "Mechanism of gallbladder relaxation in the cat: role of norepinephrine," Journal of Pharmacology and Experimental Therapeutics, vol. 285, no. 2, pp. 475-479, 1998.

[12] C. Dahlstrand, A. Dahlström, and H. Ahlman, "Adrenergic and VIP-ergic relaxatory mechanisms of the feline extrahepatic biliary tree," Journal of the Autonomic Nervous System, vol. 26, no. 2, pp. 97-106, 1989.

[13] H. Abiru, S. K. Sarna, and R. E. Condon, "Contractile mechanisms of gallbladder filling and emptying in dogs," Gastroenterology, vol. 106, no. 6, pp. 1652-1661, 1994. 
[14] L. Behar, K. Y. Lee, W. R. Thompson, and P. Biancani, "Gallbladder contraction in patients with pigment and cholesterol stones," Gastroenterology, vol. 97, no. 6, pp. 1479-1484, 1989.

[15] A. Torsoli, E. Corazziari, F. I. Habib, and M. Cicala, "Pressure relationships within the human bile tract. Normal and abnormal physiology," Scandinavian Journal of Gastroenterology, Supplement, vol. 25, no. 175, pp. 52-57, 1990.

[16] I. Takahashi, M. K. Kern, W. J. Dodds et al., "Contraction pattern of opossum gallbladder during fasting and after feeding," American Journal of Physiology, vol. 250, no. 2, pp. G227-G235, 1986.

[17] P. G. Burhol, P. L. Rayford, R. Jorde, H. L. Waldum, T. B. Schulz, and J. C. Thompson, "Radioimmunoassay of plasma cholecystokinin (CCK), duodenal release of CCK, diurnal variation of plasma CCK, and immunoreactive plasma CCK components in man," Hepato-Gastroenterology, vol. 27, no. 4, pp. 300-309, 1980.

[18] T. O. Lankisch, Y. Tsunoda, Y. Lu, and C. Owyang, "Characterization of CCKA receptor affinity states and $\mathrm{Ca}^{2+}$ signal transduction in vagal nodose ganglia," American Journal of Physiology, vol. 282, no. 6, pp. G1002-G1008, 2002.

[19] L. Gullo, L. Bolondi, P. Priori, P. Casanova, and G. Labò, "Inhibitory effect of atropine on cholecystokinin-induced gallbladder contraction in man," Digestion, vol. 29, no. 4, pp. 209-213, 1984.

[20] E. A. Boyden, "The anatomy of the choledochoduodenal junction in man," Surgery, Gynecology \& Obstetrics, vol. 104, no. 6, pp. 641-652, 1957.

[21] J. Behar and P. Biancani, "Role of cat sphincter of Oddi motor activity on trans-sphincteric flow (TSF)," Gastroenterology, vol. 88, p. 1320, 1985.

[22] R. Honda, J. Toouli, W. J. Dodds, S. Sarna, and W. J. Hogan, "Relationship of sphincter of Oddi spike bursts to gastrointestinal myoelectric activity in conscious opossums," Journal of Clinical Investigation, vol. 69, no. 4, pp. 770-778, 1982.

[23] N. Hanyu, W. J. Dodds, R. D. Layman, and W. J. Hogan, “Cholecystokinin-induced contraction of opossum sphincter of Oddi. Mechanism of action," Digestive Diseases and Sciences, vol. 35, no. 5, pp. 567-576, 1990.

[24] J. E. Geenen, W. J. Hogan, E. T. Stewart, W. J. Dodds, and R. C. Arndorffer, "ERCP manometry of the sphincter of Oddi," in The Papilla Vater and Its Diseases, M. Classen, J. E. Geenen, and K. Kawai, Eds., pp. 92-98, Witzstrock, Köln, Germany, 1979.

[25] J. Toouli and A. Craig, "Sphincter of Oddi function and dysfunction," Canadian Journal of Gastroenterology, vol. 14, no. 5, pp. 411-419, 2000.

[26] K. Ono, H. Suzuki, R. Hada, M. Sasaki, and M. Endoh, "Gastrointestinal hormones and motility of the human sphincter of Oddi," Nihon Heikatsukin Gakkai Zasshi, vol. 21, supplement, pp. 69-75, 1985.

[27] T. L. Peeters, G. Vantrappen, and J. Janssens, "Bile acid output and the interdigestive migrating motor complex in normals and in cholecystectomy patients," Gastroenterology, vol. 79, no. 4, pp. 678-681, 1980.

[28] J. Behar and P. Biancani, "Effect of cholecystokinin and the octapeptide of cholecystokinin on the feline sphincter of Oddi and gallbladder. Mechanism of action," Journal of Clinical Investigation, vol. 66, no. 6, pp. 1231-1239, 1980.

[29] J. Behar and P. Biancani, "Pharmacology of the biliary tract," in Handbook of Physiology. The Gastrointestinal System I, S. Schultz, Ed., chapter 29, pp. 1103-1131, 1989.

[30] J. F. Helm, W. J. Dodds, J. Christensen, and S. K. Sarna, "Control mechanism of spontaneous in vitro contractions of the opossum sphincter of Oddi," The American Journal of Physiology, vol. 249, no. 5, pp. G572-G579, 1985.

[31] V. Garrigues, J. Ponce, V. Pertejo, T. Sala, and J. Berenguer, "Effects of atropine and pirenzepine on sphincter of Oddi motility. A manometric study," Journal of Hepatology, vol. 3, no. 2, pp. 247-250, 1986.

[32] J. Behar and P. Biancani, "Neural control of the sphincter of Oddi. Physiologic role of enkephalins on the regulation of basal sphincter of Oddi motor activity in the cat," Gastroenterology, vol. 86, no. 1, pp. 134-141, 1984.

[33] J. Behar and P. Biancani, "Neural control of the sphincter of Oddi: a physiological role of 5-hydroxytryptamine in the regulation of basal sphincter of oddi motor activity in the cat," Journal of Clinical Investigation, vol. 72, no. 2, pp. 551-559, 1983.

[34] J. Behar and P. Biancani, "Effects of mechanisms of action of motilin on the cat sphincter of Oddi," Gastroenterology, vol. 95, no. 4, pp. 1099-1105, 1988.

[35] J. W. Wiley, T. M. O'Dorisio, and C. Owyang, "Vasoactive intestinal polypeptide mediates cholecystokinin-induced relaxation of the sphincter of Oddi," Journal of Clinical Investigation, vol. 81, no. 6, pp. 1920-1924, 1988.

[36] H. S. Kaufman, M. A. Shermak, C. A. May, H. A. Pitt, and K. D. Lillemoe, "Nitric oxide inhibits resting sphincter of Oddi activity," The American Journal of Surgery, vol. 165, no. 1, pp. 7480, 1993.

[37] I. Yamamoto, M. Fujimura, N. Kihara et al., "Nitric oxide formation in the dog sphincter of Oddi from nitric oxide donors as measured with in vivo micro-dialysis," Alimentary Pharmacology and Therapeutics, vol. 14, no. 8, pp. 1095-1101, 2000.

[38] K. Yokohata, H. Kimura, Y. Ogawa, G. Naritomi, and M. Tanaka, "Biliary motility. Changes in detailed characteristics correlated to duodenal migrating motor complex and effects of morphine and motilin in dogs," Digestive Diseases and Sciences, vol. 39, no. 6, pp. 1294-1301, 1994.

[39] Y. Tanobe, T. Okamura, M. Fujimura, and N. Toda, "Functional role and histological demonstration of nitric-oxide-mediated inhibitory nerves in dog sphincter of Oddi," Neurogastroenterology and Motility, vol. 7, no. 4, pp. 219-227, 1995.

[40] S. Mahmud, Y. Hamza, and A. H. M. Nassar, "The significance of cystic duct stones encountered during laparoscopic cholecystectomy," Surgical Endoscopy, vol. 15, no. 5, pp. 460-462, 2001.

[41] P. Paré, E. A. Shaffer, and L. Rosenthall, "Nonvisualization of the gallbladder by $99 \mathrm{~m}$ Tc-HIDA cholescintigraphy as evidence of cholecystitis," Canadian Medical Association Journal, vol. 118, no. 4, pp. 384-386, 1978.

[42] Z. L. Xiao, Q. Chen, J. Amaral, P. Biancani, and J. Behar, "Defect of receptor-G protein coupling in human gallbladder with cholesterol stones," American Journal of Physiology, vol. 278, no. 2, pp. G251-G258, 2000.

[43] A. Csendes, P. Burdiles, G. Smok, P. Csendes, A. Burgos, and M. Recio, "Histologic findings of gallbladder mucosa in 87 patients with morbid obesity without gallstones compared to 87 control subjects," Journal of Gastrointestinal Surgery, vol. 7, no. 4, pp. 547-551, 2003.

[44] P. L. Liew, W. Wang, Y. C. Lee, M. T. Huang, Y. C. Lin, and W. J. Lee, "Gallbladder disease among obese patients in Taiwan," Obesity Surgery, vol. 17, no. 3, pp. 383-390, 2007.

[45] M. P. L. Guarino, Z. L. Xiao, P. Biancani, and J. Behar, "PAFlike lipids- and PAF-induced gallbladder muscle contraction is mediated by different pathways in guinea pigs," American Journal of Physiology, vol. 285, no. 6, pp. G1189-G1197, 2003. 
[46] S. J. Baig, S. Biswas, S. Das, K. Basu, and G. Chattopadhyay, "Histopathological changes in gallbladder mucosa in cholelithiasis: correlation with chemical composition of gallstones," Tropical Gastroenterology, vol. 23, no. 1, pp. 25-27, 2002.

[47] S. Carotti, M. P. L. Guarino, M. Cicala et al., "Effect of ursodeoxycholic acid on inflammatory infiltrate in gallbladder muscle of cholesterol gallstone patients," Neurogastroenterology and Motility, vol. 22, no. 8, pp. 866-873, 2010.

[48] P. Portincasa, A. Di Ciaula, G. Vendemiale et al., "Gallbladder motility and cholesterol crystallization in bile from patients with pigment and cholesterol gallstones," European Journal of Clinical Investigation, vol. 30, no. 4, pp. 317-324, 2000.

[49] J. J. Roslyn, L. DenBesten, J. E. Thompson, and B. F. Silverman, "Roles of lithogenic bile and cystic duct occlusion in the pathogenesis of acute cholecystitis," American Journal of Surgery, vol. 140, no. 1, pp. 126-130, 1980.

[50] K. J. van Erpecum, D. Q. H. Wang, A. Moschetta et al., "Gallbladder histopathology during murine gallstone formation: relation to motility and concentrating function," Journal of Lipid Research, vol. 47, no. 1, pp. 32-41, 2006.

[51] S. P. Lee and A. J. Scott, "Dihydrocholesterol-induced gallstones in the rabbit: evidence that bile acids cause gallbladder epithelial injury," British Journal of Experimental Pathology, vol. 60, no. 3, pp. 231-238, 1979.

[52] A. J. Scott, "Epithelial cell proliferation in diverse models of experimental cholelithiasis," Gut, vol. 19, no. 6, pp. 558-562, 1978.

[53] M. R. Jacyna, P. E. Ross, M. A. Bakar, D. Hopwood, and I. A. Bouchier, "Characteristics of cholesterol absorption by human gall bladder: relevance to cholesterolosis," Journal of Clinical Pathology, vol. 40, no. 5, pp. 524-529, 1987.

[54] W. W. LaMorte, M. L. Booker, T. E. Scott, and L. F. Williams Jr., "Increases in gallbladder prostaglandin synthesis before the formation of cholesterol gallstones," Surgery, vol. 98, no. 3, pp. 445-451, 1985.

[55] L. Jivegård, G. Rådberg, and T. Wahlin, "An experimental study on the role of gallbladder mucosal fluid secretion and intraluminal pressure in cholecystitis," Acta Chirurgica Scandinavica, vol. 152, pp. 605-610, 1986.

[56] R. Kuver, C. Savard, D. Oda, and S. P. Lee, "PGE generates intracellular cAMP and accelerates mucin secretion by cultured dog gallbladder epithelial cells," American Journal of Physiology, vol. 267, no. 6, pp. G998-G1003, 1994.

[57] J. Lamote and G. Willems, "DNA synthesis, cell proliferation index in normal and abnormal gallbladder epithelium," Microscopy Research and Technique, vol. 38, no. 6, pp. 609-615, 1997.

[58] B. R. MacPherson, R. S. Pemsingh, and G. W. Scott, "Experimental cholelithiasis in the ground squirrel," Laboratory Investigation, vol. 56, no. 2, pp. 138-145, 1987.

[59] P. Yu, Q. Chen, P. Biancani, and J. Behar, "Membrane cholesterol alters gallbladder muscle contractility in prairie dogs," American Journal of Physiology, vol. 271, no. 1, pp. G62-G67, 1996.

[60] Z. Xiao, F. Schmitz, V. E. Pricolo, P. Biancani, and J. Behar, "Role of caveolae in the pathogenesis of cholesterol-induced gallbladder muscle hypomotility," American Journal of Physiology, vol. 292, no. 6, pp. G1641-G1649, 2007.

[61] P. G. Frank, S. Pavlides, M. W. C. Cheung, K. Daumer, and M. P. Lisanti, "Role of caveolin-1 in the regulation of lipoprotein metabolism," American Journal of Physiology, vol. 295, no. 1, pp. C242-C248, 2008.
[62] P. Cong, V. Pricolo, P. Biancani, and J. Behar, "Effects of cholesterol on CCK-1 receptors and caveolin-3 proteins recycling in human gallbladder muscle," American Journal of Physiology, vol. 299, no. 3, pp. G742-G750, 2010.

[63] Z. L. Xiao, Q. Chen, J. Amaral, P. Biancani, R. T. Jensen, and J. Behar, "CCK receptor dysfunction in muscle membranes from human gallbladders with cholesterol stones," American Journal of Physiology, vol. 276, no. 6, pp. G1401-G1407, 1999.

[64] J. Behar, B. Y. Rhim, W. Thompson, and P. Biancani, "Inositol trisphosphate restores impaired human gallbladder motility associated with cholesterol stones," Gastroenterology, vol. 104, no. 2, pp. 563-568, 1993.

[65] Q. Chen, J. Amaral, S. Oh, P. Biancani, and J. Behar, "Gallbladder relaxation in patients with pigment and cholesterol stones," Gastroenterology, vol. 113, no. 3, pp. 930-937, 1997.

[66] L. Zhang, A. D. Bonev, M. T. Nelson, and G. M. Mawe, "Ionic basis of the action potential of guinea pig gallbladder smooth muscle cells," American Journal of Physiology, vol. 265, no. 6, pp. C1552-C1561, 1993.

[67] L. J. Jennings, Q. W. Xu, T. A. Firth, M. T. Nelson, and G. M. Mawe, "Cholesterol inhibits spontaneous action potentials and calcium currents in guinea pig gallbladder smooth muscle," American Journal of Physiology, vol. 277, no. 5, pp. G1017-G1026, 1999.

[68] S. Morales, P. J. Camello, G. M. Mawe, and M. J. Pozo, "Characterization of intracellular $\mathrm{Ca}^{2+}$ stores in gallbladder smooth muscle," American Journal of Physiology, vol. 288, no. 3, pp. G507-G513, 2005.

[69] M. Xie, V. R. Kotecha, J. D. Andrade, J. G. Fox, and M. C. Carey, "Augmented cholesterol absorption and sarcolemmal sterol enrichment slow small intestinal transit in mice, contributing to cholesterol cholelithogenesis," The Journal of Physiology, vol. 590, pp. 1811-1824, 2012.

[70] B. Lavoie, B. Nausch, E. A. Zane et al., "Disruption of gallbladder smooth muscle function is an early feature in the development of cholesterol gallstone disease," Neurogastroenterology \& Motility, vol. 24, no. 7, pp. e313-e324, 2012.

[71] S. I. Myers, D. Haley-Russell, L. Parks, and K. Husband, "Common bile duct ligation in rabbit: a new model of acute cholecystitis description of histology and bile analysis," Journal of Surgical Research, vol. 45, no. 6, pp. 556-564, 1988.

[72] Z. L. Xiao, P. Biancani, M. C. Carey, and J. Behar, "Hydrophilic but not hydrophobic bile acids prevent gallbladder muscle dysfunction in acute cholecystitis," Hepatology, vol. 37, no. 6, pp. 1442-1450, 2003.

[73] C. Jüngst, N. Sreejayan, B. Zündt et al., "Ursodeoxycholic acid reduces lipid peroxidation and mucin secretagogue activity in gallbladder bile of patients with cholesterol gallstones," European Journal of Clinical Investigation, vol. 38, no. 9, pp. 634-639, 2008.

[74] Z. L. Xiao, A. K. Rho, P. Biancani, and J. Behar, "Effects of bile acids on the muscle functions of guinea pig gallbladder," American Journal of Physiology, vol. 283, no. 1, pp. G87-G94, 2002.

[75] B. Lavoie, O. B. Balemba, C. Godfrey et al., "Hydrophobic bile salts inhibit gallbladder smooth muscle function via stimulation of GPBAR1 receptors and activation of KATP channels," Journal of Physiology, vol. 588, no. 17, pp. 3295-3305, 2010.

[76] M. P. L. Guarino, S. Carotti, S. Morini et al., "Decreased number of activated macrophages in gallbladder muscle layer of cholesterol gallstone patients following ursodeoxycholic acid," Gut, vol. 57, no. 12, pp. 1740-1741, 2008. 
[77] S. Tomida, M. Abei, T. Yamaguchi et al., "Long-term ursodeoxycholic acid therapy is associated with reduced risk of biliary pain and acute cholecystitis in patients with gallbladder stones: a cohort analysis," Hepatology, vol. 30, no. 1, pp. 6-13, 1999.

[78] D. Q. H. Wang, S. Tazuma, D. E. Cohen, and M. C. Carey, "Feeding natural hydrophilic bile acids inhibits intestinal cholesterol absorption: studies in the gallstone-susceptible mouse," American Journal of Physiology, vol. 285, no. 3, pp. G494-G502, 2003.

[79] Z. L. Xiao, P. Biancani, and J. Behar, "Role of PGE2 on gallbladder muscle cytoprotection of guinea pigs," American Journal of Physiology, vol. 286, no. 1, pp. G82-G88, 2004.

[80] Z. L. Xiao, J. Amaral, P. Biancani, and J. Behar, "Impaired cytoprotective function of muscle in human gallbladders with cholesterol stones," American Journal of Physiology, vol. 288, no. 3, pp. G525-G532, 2005.

[81] Q. Chen, V. Chitinavis, Z. Xiao et al., "Impaired G protein function in gallbladder muscle from progesterone- treated guinea pigs," American Journal of Physiology, vol. 274, no. 2, pp. G283G289, 1998.

[82] P. Cong, V. Pricolo, P. Biancani, and J. Behar, "High levels of caveolar cholesterol inhibit progesterone-induced genomic actions in human and guinea pig gallbladder muscle," American Journal of Physiology, vol. 296, no. 4, pp. G948-G954, 2009.

[83] H. H. Wang, N. H. Afdhal, and D. Q. H. Wang, "Estrogen receptor $\alpha$, but not $\beta$, plays a major role in $17 \beta$-estradiolinduced murine cholesterol gallstones," Gastroenterology, vol. 127, no. 1, pp. 239-249, 2004.

[84] A. Moschetta, M. F. J. Stolk, J. F. Rehfeld et al., "Severe impairment of postprandial cholecystokinin release and gall-bladder emptying and high risk of gallstone formation in acromegalic patients during Sandostatin LAR," Alimentary Pharmacology and Therapeutics, vol. 15, no. 2, pp. 181-185, 2001.

[85] H. H. Wang, P. Portincasa, M. Liu, P. Tso, L. C. Samuelson, and D. Q. H. Wang, "Effect of gallbladder hypomotility on cholesterol crystallization and growth in CCK-deficient mice," Biochimica et Biophysica Acta, vol. 1801, no. 2, pp. 138-146, 2010.

[86] R. H. Dowling, "Review: pathogenesis of gallstones," Alimentary Pharmacology and Therapeutics, vol. 14, supplement 2, pp. 3947, 2000.

[87] J. S. Dooley, S. F. Anna, K. Lock, E. Burroughs, and J. Heathcote, Gallstones and Benign Biliary Disease, chapter 12, Blackwell, 2011.

[88] S. M. Strasberg and P.-A. Clavien, "Acute calculous cholecystitis," in Gastroenterology, W. S. Haubrich, F. Schaffner, and J. E. Berk, Eds., vol. 3, chapter 137, pp. 2635-2664, Saunders, Philadelphia, Pa, USA, 5th edition, 1995.

[89] D. Festi, M. L. B. Reggiani, A. F. Attili et al., "Natural history of gallstone disease: expectant management or active treatment? Results from a population-based cohort study," Journal of Gastroenterology and Hepatology, vol. 25, no. 4, pp. 719-724, 2010.

[90] L. J. Bennion, W. C. Knowler, D. M. Mott, A. M. Spagnola, and P. H. Bennett, "Development of lithogenic bile during puberty in Pima Indians," The New England Journal of Medicine, vol. 300, no. 16, pp. 873-876, 1979.

[91] R. E. Sampliner, P. H. Bennett, L. J. Comess, F. A. Rose, and T. A. Burch, "Gallbladder disease in pima indians. Demonstration of high prevalence and early onset by cholecystography," The New England Journal of Medicine, vol. 283, no. 25, pp. 1358-1364, 1970.

[92] J. F. Miquel, C. Covarrubias, L. Villaroel et al., "Genetic epidemiology of cholesterol cholelithiasis among Chilean Hispanics,
Amerindians, and Maoris," Gastroenterology, vol. 115, no. 4, pp. 937-946, 1998

[93] A. Martínez, X. Bona, M. Velasco, and J. Martín, "Diagnostic accuracy of ultrasound in acute cholecystitis," Gastrointestinal Radiology, vol. 11, no. 4, pp. 334-338, 1986.

[94] K. J. Mortelé and P. R. Ros, "Anatomic variants of the biliary tree: MR cholangiographic findings and clinical applications," American Journal of Roentgenology, vol. 177, no. 2, pp. 389-394, 2001.

[95] P. E. Jaffe, "Gallstones: who are good candidates for nonsurgical treatment?" Postgraduate Medicine, vol. 94, no. 6, pp. 45-57, 1993.

[96] M. C. Weinstein, C. M. Coley, and J. M. Richter, "Medical management of gallstones: a cost-effectiveness analysis," Journal of General Internal Medicine, vol. 5, no. 4, pp. 277-284, 1990.

[97] J. Velasco, J. Singh, P. Ramanujam, and M. Friedberg, "Hepatobiliary scanning in cholecystitis," European Journal of Nuclear Medicine, vol. 7, no. 1, pp. 11-13, 1982.

[98] A. van Randen, W. Laméris, H. W. van Es et al., "A comparison of the accuracy of ultrasound and computed tomography in common diagnoses causing acute abdominal pain," European Radiology, vol. 21, no. 7, pp. 1535-1545, 2011.

[99] W. F. Fallon Jr., J. S. Newman, G. L. Fallon, and M. A. Malangoni, "The surgical management of intra-abdominal inflammatory conditions during pregnancy," Surgical Clinics of North America, vol. 75, no. 1, pp. 15-31, 1995.

[100] J. M. Wu, Y. M. Wu, C. Y. Lee, H. P. Wang, and M. T. Lin, "Is early laparoscopic cholecystectomy a safe procedure in patients when the duration of acute cholecystitis is more than three days?" Hepatogastroenterology, vol. 59, pp. 10-12, 2012.

[101] J. Behar, E. Corazziari, M. Guelrud, W. Hogan, S. Sherman, and J. Toouli, "Functional gallbladder and sphincter of oddi disorders," Gastroenterology, vol. 130, no. 5, pp. 1498-1509, 2006.

[102] M. Cicala, F. I. Habib, P. Vavassori et al., "Outcome of endoscopic sphincterotomy in post cholecystectomy patients with sphincter of Oddi dysfunction as predicted by manometry and quantitative choledochoscintigraphy," Gut, vol. 50, no. 5, pp. 665-668, 2002.

[103] J. E. Geenen, W. J. Hogan, W. J. Dodds, J. Toouli, and R. P. Venu, "The efficacy of endoscopic sphingerotomy after cholecystectomy in patients with sphincter-of-Oddi dysfunction," The New England Journal of Medicine, vol. 320, no. 2, pp. 82-87, 1989.

[104] H. Meshkinpour, L. Kay, and M. Mollot, "The role of the flow rate of the pneumohydraulic system on post-sphincter of oddi manometry pancreatitis," Journal of Clinical Gastroenterology, vol. 14, no. 3, pp. 236-239, 1992.

[105] W. Hogan, J. Geenen, W. Dodds, J. Touli, R. Venu, and J. Helm, "Paradoxical motor response to cholecystokinin (CCK-OP) in patients with suspected sphincter of Oddi dysfunction," Gastroenterology, vol. 82, no. 5, p. 1085, 1982.

[106] T. Wehrmann, H. Seifert, M. Seipp, B. Lembcke, and W. F. Caspary, "Endoscopic injection of botulinum toxin for biliary sphincter of oddi dysfunction," Endoscopy, vol. 30, no. 8, pp. 702-707, 1998.

[107] L. Xiao, J. Cheng, J. Dai, and D. Zhang, "Botulinum toxin decreases hyperalgesia and inhibits $\mathrm{P}_{2} \mathrm{X}_{3}$ receptor over-expression in sensory neurons induced by ventral root transection in rats," Pain Medicine, vol. 12, no. 9, pp. 1385-1394, 2011. 

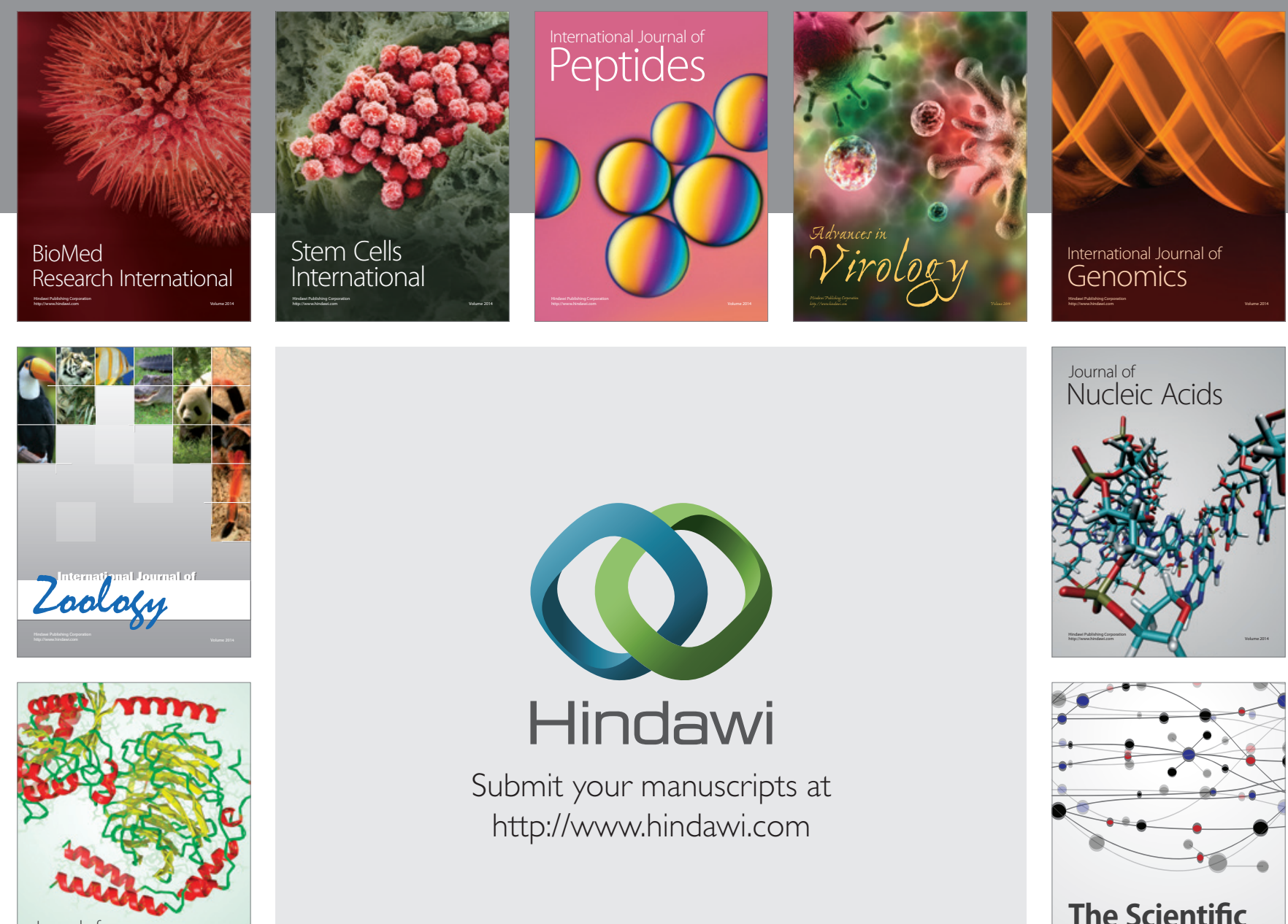

Submit your manuscripts at

http://www.hindawi.com

Journal of
Signal Transduction
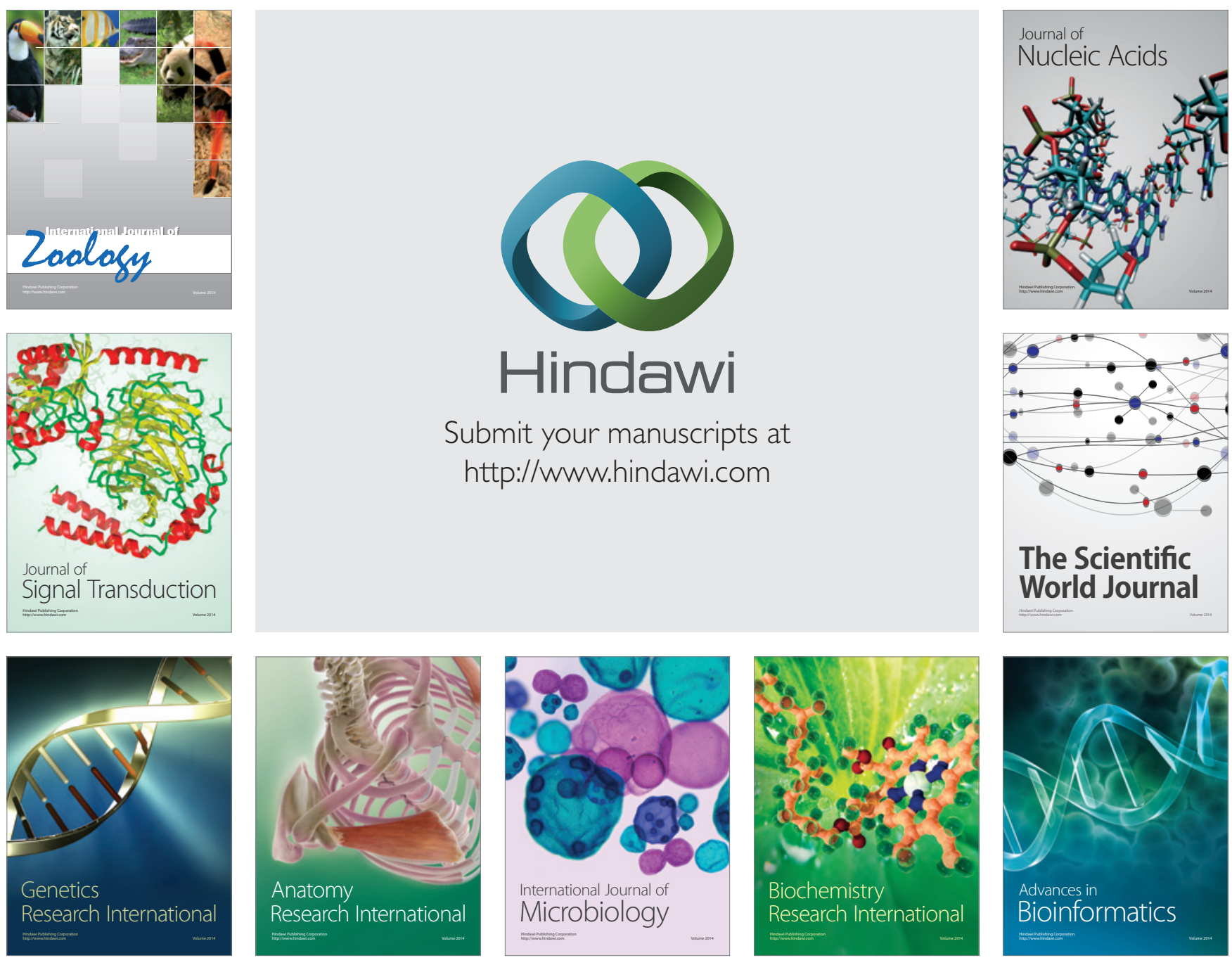

The Scientific World Journal
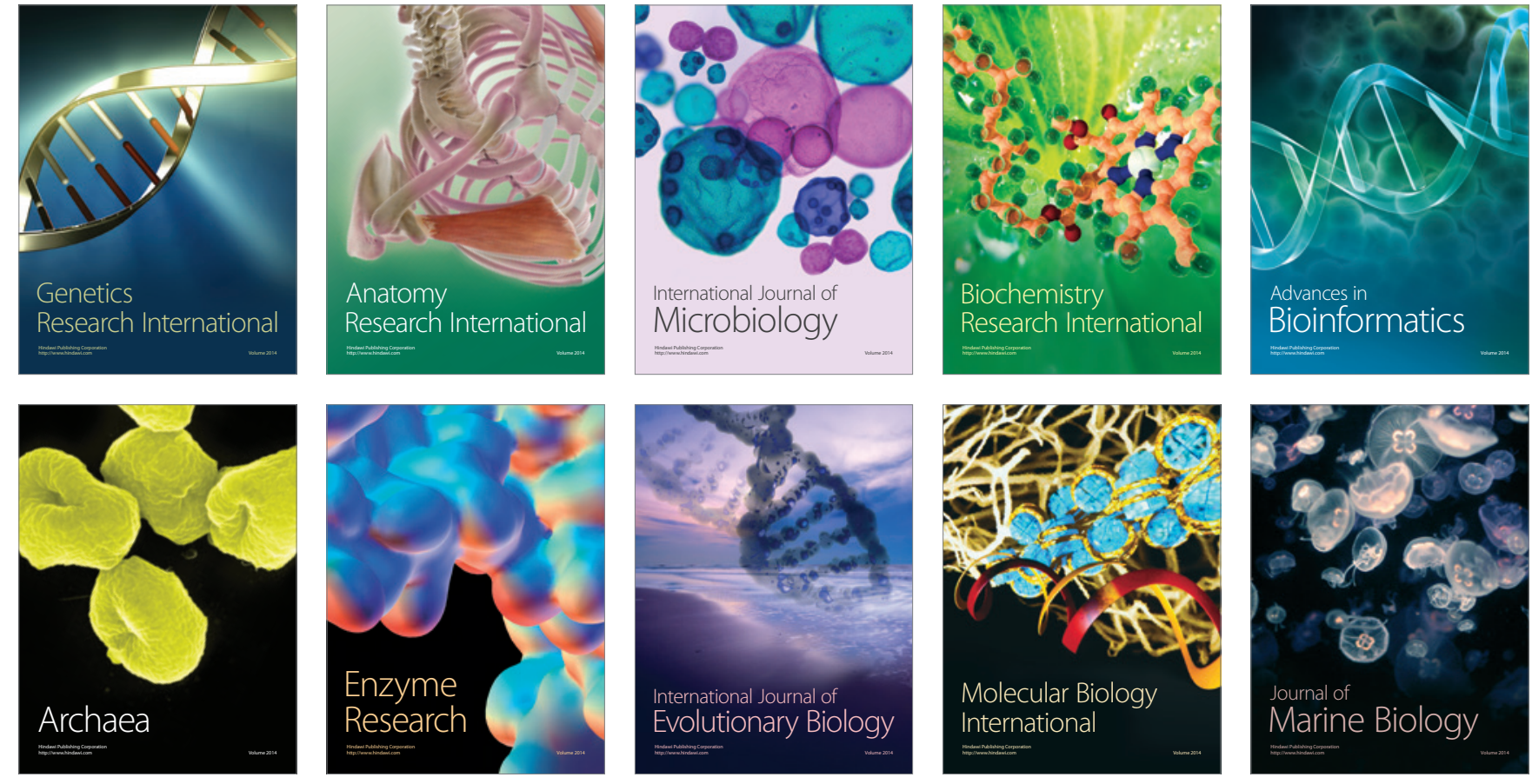